\title{
Engineering a wild-type diploid Saccharomyces cerevisiae strain for second-generation bioethanol production
}

\author{
Hongxing $\mathrm{Li}^{1,2+}$, Yu Shen ${ }^{1 \dagger}$, Meiling Wu${ }^{1}$, Jin Hou${ }^{1}$, Chunlei Jiao ${ }^{1}$, Zailu Li ${ }^{2}$, Xinli Liu² and Xiaoming Bao ${ }^{1,2^{*}}$
}

\begin{abstract}
Background: The cost-effective production of second-generation bioethanol, which is made from lignocellulosic materials, has to face the following two problems: co-fermenting xylose with glucose and enhancing the strain's tolerance to lignocellulosic inhibitors. Based on our previous study, the wild-type diploid Saccharomyces cerevisiae strain BSIF with robustness and good xylose metabolism genetic background was used as a chassis for constructing efficient xylose-fermenting industrial strains. The performance of the resulting strains in the fermentation of media with sugars and hydrolysates was investigated.

Results: The following two novel heterologous genes were integrated into the genome of the chassis cell: the mutant MGT05196 $6^{\mathrm{N} 360 \mathrm{~F}}$, which encodes a xylose-specific, glucose-insensitive transporter and is derived from the Meyerozyma guilliermondii transporter gene MGT05196, and Ru-xyIA (where Ru represents the rumen), which encodes a xylose isomerase (XI) with higher activity in S. cerevisiae. Additionally, endogenous modifications were also performed, including the overproduction of the xylulokinase Xks1p and the non-oxidative PPP (pentose phosphate pathway), and the inactivation of the aldose reductase Gre3p and the alkaline phosphatase Pho13p. These rationally designed genetic modifications, combined with alternating adaptive evolutions in xylose and SECS liquor (the leach liquor of steam-exploding corn stover), resulted in a final strain, LF1, with excellent xylose fermentation and enhanced inhibitor resistance. The specific xylose consumption rate of LF1 reached as high as $1.089 \mathrm{~g} \mathrm{~g}^{-1} \mathrm{~h}^{-1}$ with xylose as the sole carbon source. Moreover, its highly synchronized utilization of xylose and glucose was particularly significant; $77.6 \%$ of xylose was consumed along with glucose within $12 \mathrm{~h}$, and the ethanol yield was $0.475 \mathrm{~g} \mathrm{~g}^{-1}$, which is more than 93\% of the theoretical yield. Additionally, LF1 performed well in fermentations with two different lignocellulosic hydrolysates.
\end{abstract}

Conclusion: The strain LF1 co-ferments glucose and xylose efficiently and synchronously. This result highlights the great potential of LF1 for the practical production of second-generation bioethanol.

Keywords: Xylose-specific transporter, Xylose isomerase, Synchronous utilization of xylose and glucose, Lignocellulosic ethanol, Budding yeast

\section{Background}

Bioethanol produced from lignocellulose, i.e., secondgeneration bioethanol, is benefit for a sustainable energy supply. Its cost-effective production process depends on

\footnotetext{
*Correspondence: bxm@sdu.edu.cn

${ }^{\dagger}$ Hongxing Li and Yu Shen considered as joint first authors

1 State Key Laboratory of Microbial Technology, Shandong University,

Shan Da Nan Road 27, Jinan 250100, China

Full list of author information is available at the end of the article
}

the complete and rapid utilization of all the sugars in the hydrolysates derived from lignocellulosic raw materials (Ko et al. 2016; Moysés et al. 2016; Peng et al. 2012; Zhou et al. 2012). The budding yeast Saccharomyces cerevisiae is a prominent microorganism that has traditionally been used in industrial bioethanol production because of its numerous inherent advantages (Demeke et al. 2013). However, this natural ethanol producer must overcome at least two new challenges when the 
fermentation substrate is lignocellulosic hydrolysates, rather than starch-based materials. First, natural S. cerevisiae cannot effectively metabolize pentose sugars, particularly D-xylose, the second most abundant sugar in lignocellulosic materials because it lacks an effective initial metabolic pathway (Hahn-Hägerdal et al. 2007; van Maris et al. 2006). Second, the individual and synergistic negative interactions derived from the numerous inhibitory compounds that are formed during the pretreatment process and the hydrolytic release of sugars exert serious negative effects on the fermentation performance of $S$. cerevisiae (Ko et al. 2016; Palmqvist and Hahn-Hägerdal 2000). Therefore, for the economically viable and sustainable production of lignocellulosic bioethanol, it is necessary to confer the capacity to co-ferment glucose and xylose on an S. cerevisiae strain and to enhance its resistance to harsh production environments (Demeke et al. 2013; Li et al. 2015; Sharma et al. 2016).

The genetic background of the host strain significantly affects the performance of the recombinant strain. Normally, despite strain variation, polyploid, wild-type $S$. cerevisiae is a better ethanol producer than the haploid strain, which is generally used in the laboratory (Brandberg et al. 2004; Li et al. 2015; Sonderegger et al. 2004; Yamada et al. 2011). Although the genetic background issue is complex, basic selection principles are feasible. By evaluating strains for their glucose-fermenting power, stress tolerance, and the ability to metabolize pentose, we can select a strain suitable for use as the chassis cell in lignocellulosic ethanol production ( $\mathrm{Li}$ et al. 2015).
The following two heterologous initial xylose metabolic pathways (Fig. 1a) were introduced into an S. cerevisiae strain: the XR-XDH pathway, which is composed of xylose reductase (XR) and xylitol dehydrogenase $(\mathrm{XDH})$, and the XI pathway, which is composed only of xylose isomerase (XI). For the XR-XDH pathway, xylose is first converted to xylitol by XR, which has a higher affinity for NADPH than NADH. Then, xylitol is oxidized into xylulose by $\mathrm{XDH}$, which depends exclusively on NAD ${ }^{+}$(Ho et al. 1999; Peng et al. 2012; Wang et al. 2004). The imbalance in redox metabolism caused by the different coenzyme preferences between XR and XDH result in the accumulation of the byproduct xylitol and a lower ethanol yield; cofactor engineering resulted in limited improvement (Hou et al. 2009a; Zha et al. 2012; Zhang et al. 2010). For the XI pathway, since xylose is directly isomerized to xylulose with no coenzyme participation, incorporating this pathway is a direct and effective strategy for initiating xylose metabolism in $S$. cerevisiae (Demeke et al. 2013; Diao et al. 2013; Zhou et al. 2012). Highly efficient XI activity is a prerequisite for rapid and efficient xylose fermentation in $S$. cerevisiae (Brat et al. 2009; Kuyper et al. 2003; Madhavan et al. 2009; Walfridsson et al. 1996; Zhou et al. 2012). Recently, we screened a bovine rumen metagenomic library and discovered the novel XI gene Ru-xylA. Ru-XI exhibited higher activity $\left(1.31 \mathrm{U} \mathrm{mg}^{-1}\right)$ in $S$. cerevisiae (Bao et al. 2013; Hou et al. 2016a) than Pi-XI (the XI from Piromyces sp.), which is a prototypically active XI (Kuyper et al. 2003, 2004).

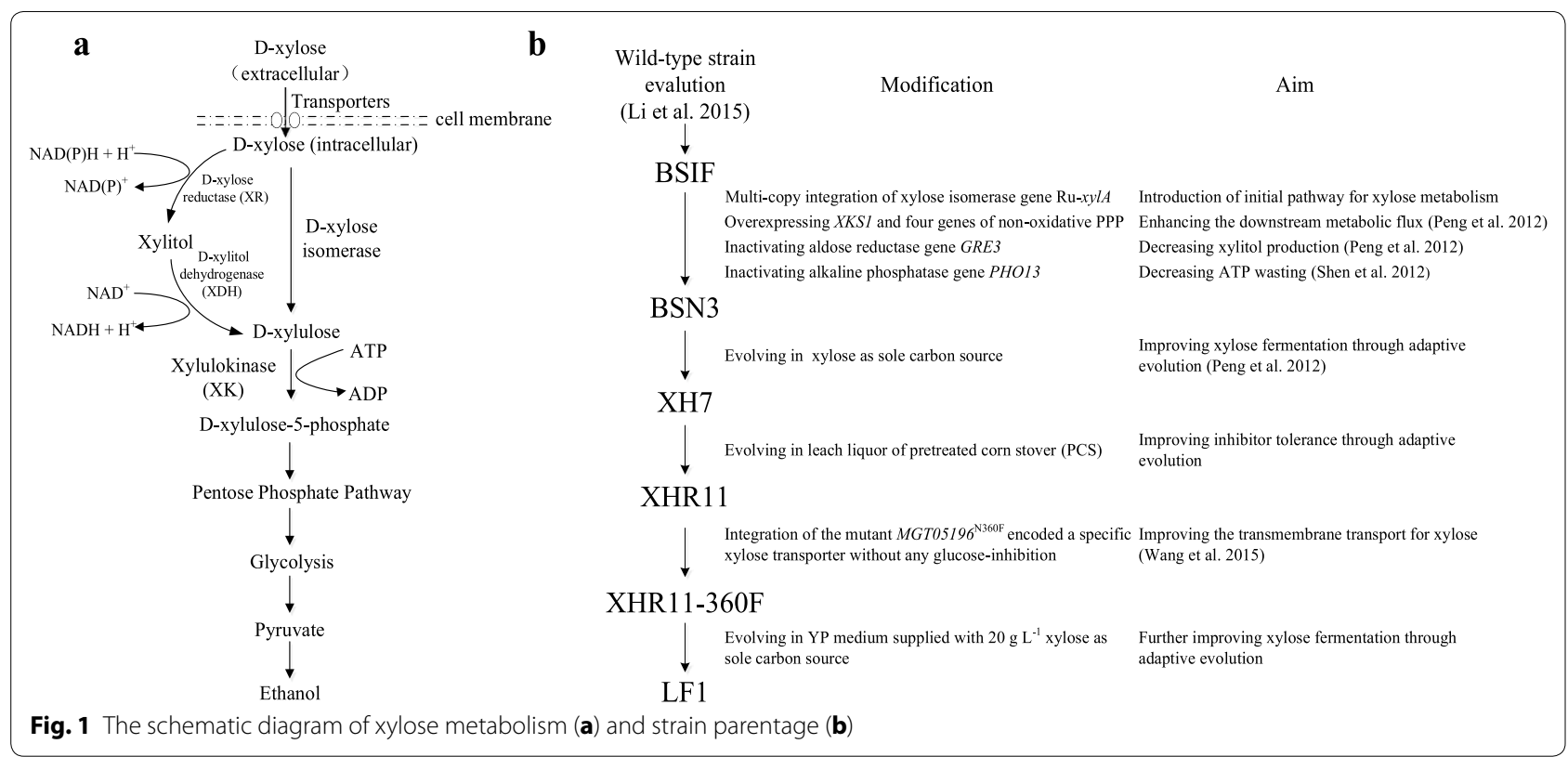


To compensate for the shortfall in downstream metabolic flux in ethanol production, the xylulokinase Xks1p and the enzymes in the non-oxidative PPP are normally overexpressed in a xylose-utilizing strain (Bamba et al. 2016; Peng et al. 2012; Sharma et al. 2016). Additionally, the inactivation of aldose reductase Gre3p, which is encoded by GRE3, to decrease the formation of the byproduct xylitol (Bamba et al. 2016; Fujitomi et al. 2012; Hahn-Hägerdal et al. 2007; Kuyper et al. 2005a; Peng et al. 2012), and the inactivation of alkaline phosphatase Pho13p, encoded by PHO13, to reduce ATP waste (Bamba et al. 2016; Lee et al. 2014; Shen et al. 2012; Van Vleet et al. 2008), were also the considered strategies. Normally, xylose is absorbed non-specifically and insufficiently by hexose transporters and is competitively inhibited by glucose in S. cerevisiae (Subtil and Boles 2012). Therefore, to address this problem, both wild-type and mutated endogenous and heterologous transporters were screened (Diao et al. 2013; Farwick et al. 2014; Moon et al. 2013; Nijland et al. 2014; Runquist et al. 2009; Shin et al. 2015; Wang et al. 2015, 2016). Moreover, with higher efficiency and/or specificity for xylose, a transporter lacking glucose inhibition may relieve the glucose repression effect in a xylose absorption node, thereby increasing xylose metabolism. Recently, we found the mutant MGT05196 ${ }^{\mathrm{N} 360 \mathrm{~F}}$, which is derived from the Meyerozyma guilliermondii transporter gene MGT05196 and exhibits xylose-specific transport and no glucose inhibition (Wang et al. 2015).

In theory, such rational genetic modifications should endow $S$. cerevisiae with the capacity to ferment xylose; nonetheless, the xylose-fermentation efficiency of the resulting engineered strain was less than expected, indicating the influence of unknown key factors. Additionally, it remains difficult to rationally enhance the tolerance of a xylose-fermenting strain to the inhibitors present in lignocellulosic hydrolysates. Therefore, non-rational, adaptive evolutions were performed in media that contained xylose as the sole carbon source or toxic lignocellulosic hydrolysates to further select for enhanced characteristics both in xylose metabolism efficiency and robustness (Heer and Sauer 2008; Kuyper et al. 2005b; Moysés et al. 2016; Sharma et al. 2016).

The co-fermentation of hexose and pentose is considered important for the effective industrial production of bioethanol. Normally, the concept of co-fermentation usually encompasses only a strain's ability to ferment xylose and glucose in the presence of both sugars. Therefore, little attention is given to the synchronous fermentation of both sugars. In fact, the obvious hysteresis of xylose fermentation compared with glucose has been extensively observed, manifestations of which exhibit a delay not only with respect to initial xylose utilization and the xylose consumption rate but also the time to maximum ethanol production; in other words, the ethanol production value increases incrementally after glucose exhaustion (Ko et al. 2016; Peng et al. 2012; Reider Apel et al. 2016; Sharma et al. 2016). Therefore, a yeast strain that co-ferments xylose and glucose with the same consumption rate (i.e., synchronously) would be ideal. We believe that the synchronization of sugar fermentation will reduce the apparent fermentation time, improve equipment utilization and employee effectiveness, and play a vital role in the realization of the scaled-up production of second-generation bioethanol.

In the present work, the diploid S. cerevisiae strain BSIF, which we have previously shown to be robust and to possess a good background for xylose metabolism (Li et al. 2015), was used as the chassis cell. For rational strain design, two novel proprietary heterologous genes, $M^{2}$ TT05196 ${ }^{\text {N360F }}$ (ZL 2014105263569) (Wang et al. 2015) and the Ru-xylA (US 8,586,336 B2, EP 2679686, ZL 201110042170.2) (Bao et al. 2013; Hou et al. 2016a), were integrated into the genome of diploid strain BSIF. Together with other strategies, including the overexpression of the genes XKS1 (xylulokinase), TAL1 (transaldolase), TKL1 (transketolase), RKI1 (ribose 5-phosphate isomerase) and RPE1 (ribulose 5-phosphate epimerase) in the non-oxidative PPP and the inactivation of GRE3 (aldose reductase) and PHO13 (alkaline phosphatase), a functional xylose metabolic pathway was constructed in BSIF. For non-rational strain design, the recombinant cells were alternately cultured in media using xylose as the sole carbon source or SECS liquor (the leach liquor of steam-exploding corn stover) as stresses for adaptive evolution.

\section{Results}

\section{Construction of xylose-fermenting S. cerevisiae strains}

The robust diploid $S$. cerevisiae strain BSIF, which exhibits good performance in fermentation and high tolerance stress (Table 1) (Li et al. 2015), was chosen as a host for the construction of xylose-fermenting recombinant strains for bioethanol production from lignocellulose. Multiple genetic modifications were made to the genome. After each modification, approximately one dozen colonies were evaluated, and the best-growing colony was used in subsequent work. The process is described in detail as follows (Fig. 1b).

Several copies of Ru-xylA (Bao et al. 2013) were integrated into the two alleles of the PHO13 locus and the $\delta$ region in turn (Additional file 1: Fig. S1a, b). By replacing the two alleles of the native promoter with the stronger TEF1p in situ, the Xks1p gene XKS1 was overexpressed (Additional file 1: Fig. S1c) (Peng et al. 2011). The four non-oxidative PPP genes TAL1, TKL1, RKI1 and RPE1 
Table 1 Strains and plasmids used in this study

\begin{tabular}{|c|c|c|}
\hline Strain/plasmid & Genotype/properties & Resource/reference \\
\hline \multicolumn{3}{|c|}{ Saccharomyces cerevisiae } \\
\hline BSIF & Diploid S. cerevisiae strain isolated from tropical fruit in Thailand & Laboratory preserved (Li et al. 2015) \\
\hline BSN3 & $\begin{array}{l}\text { BSIF derivative; XKS1p:: loxP-TEF1p, gre3:: TPI1p-RKI1-RKI1t-PGK1p-TAL1-TAL1t-FBA1p- } \\
\text { TKL1-TKL1t-ADH1p-RPE1-RPE1t-loxP, pho13:: (TEF1p-RU-xyIA-PGK1t)-loxP, three rounds } \\
\text { of } \delta \text {-integration with a fragment containing three tandem expression cassettes of } \\
\text { Ru-xyIA and the selectable marker loxP-KanMX4-IoxP }\end{array}$ & The present work \\
\hline $\mathrm{XH7}$ & Single-colony isolate from adaptive evolution in xylose; based on BSN3 & The present work \\
\hline XHR11 & Single-colony isolate from adaptive evolution in SECS liquor; based on XH7 & The present work \\
\hline XH7-N360F & XH7 derivative; gre3::MGT05196 & The present work \\
\hline XHR11-N360F & XHR11 derivative; gre3::MGT05196 N360F & The present work \\
\hline LF1 & Single-colony isolate from adaptive evolution in xylose; based on XHR11-N360F & The present work \\
\hline \multicolumn{3}{|l|}{ Plasmids } \\
\hline pUG6 & E.coli plasmid with segment LoxP-KanMX4-LoxP & Güldener et al. (1996) \\
\hline pJX7 & pJFE3; TEF1p-Ru-xy|A-PGK1t & Bao et al. (2013) \\
\hline pXIP1 & $\begin{array}{l}\text { pUC19-based yeast integration plasmid containing the } P H O 13 \text {-targeting recombinant } \\
\text { arms PHO13-RA1 and PHO13-RA2, three tandem expression cassettes of Ru-xylA and } \\
\text { the selectable marker loxP-KanMX4-IOXP }\end{array}$ & The present work \\
\hline pXIP2 & $\begin{array}{l}\text { Similar to pXIP1; the recombinant arms PHO13-RA2 in pXIP1 were replaced with } \\
\text { PHO13-RA3 in PXIP2 }\end{array}$ & The present work \\
\hline 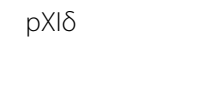 & $\begin{array}{l}\text { pUC19-based yeast integration plasmid containing the } \delta \text {-sequence-targeting recom- } \\
\text { binant arms, three tandem expression cassettes of Ru-xylA and the selectable marker } \\
\text { loxP-KanMX-IOXP }\end{array}$ & The present work \\
\hline pJPPP3 & $\begin{array}{l}\text { pUC19-based yeast integration plasmid containing the GRE3-targeting recombinant } \\
\text { arms RA1/2; an expression cassette for SC-RKI1, SC-TAL1, SC-TKL1 and SC-RPE1; and the } \\
\text { selectable marker loXP-KanMX4-loXP }\end{array}$ & Peng et al. (2012) \\
\hline pJPPP4 & $\begin{array}{l}\text { The GRE3-targeting recombinant arms GRE3-RA2 in pJPPP3 were replaced with GRE3- } \\
\text { RA3 in pJPPP4 }\end{array}$ & The present work \\
\hline pUC-N360F & $\begin{array}{l}\text { pUC19-based yeast integration plasmid containing GRE3-targeting recombinant arms, } \\
\text { an overexpression cassette for MGT05196 }{ }^{\mathrm{N} 360 \mathrm{~F}} \text {, the upstream activating sequence } \\
\text { (UAS elements) } \mathrm{UAS}_{\mathrm{CLB}} \text {, and the selectable marker loxP-KanMX4-loxP }\end{array}$ & The present work \\
\hline YEp-CH & YEp24 derivative; GAL1p-Cre-CYC1t, TEF1p-hygB-TEF1t & Laboratory preserved \\
\hline
\end{tabular}

were upregulated by insertion into the two alleles of the GRE3 locus (Additional file 1: Fig. S1d). Therefore, the genes PHO13 and GRE3 were inactivated at the same time (Additional file 1: Fig. S1a, d). After transformant evaluation, the resulting strain BSN3 (Fig. 1b) was selected for the first round of adaptive evolution. The cells were grown under the stress of xylose as a sole carbon source in YP (which was composed of $10 \mathrm{~g} \mathrm{~L}^{-1}$ yeast extract and $20 \mathrm{~g} \mathrm{~L}^{-1}$ peptone) and transferred into fresh medium once the stationary phase was reached. After $360 \mathrm{~h}$ of adaptive incubation on xylose, the biomass doubling time $(T)$ dropped from $\sim 200$ to $\sim 120 \mathrm{~min}$ and remained unchanged for several batches. Among the tested isolates, the colony that grew fastest on xylose was named XH7 (Fig. 1b). Then, to enhance the strain's tolerance to inhibitors, $\mathrm{XH7}$ was transferred into the SECS liquor with urea as a nitrogen source for another round of adaptive evolution. The concentrations of the main components in the SECS liquor are shown in Table 2.
After $\sim 900 \mathrm{~h}$ of evolution, the culture showed gradually improved growth; the biomass doubling time $(T)$ in SECS liquor shortened from $\sim 7$ to $3.9 \mathrm{~h}$. The evolved cell populations were spread on SECS liquor-agar plates. The single colony that grew best in SECS liquor was designated XHR11 (Fig. 1b).

To further enhance xylose utilization, the mutant transporter gene MGT05196 $\mathrm{N360 \textrm {F }}$, which encodes a xylosespecific, glucose-insensitive transporter (Wang et al. 2015), was introduced into another region of the GRE3 locus in XHR11 (Additional file 1: Fig. S1d). The resulting strain, XHR11-N360F (Fig. 1b), was then evolved in a medium using xylose as the sole carbon source again. After $\sim 200 \mathrm{~h}$ of adaptive evolution, the biomass doubling time $(T)$ dropped from $\sim 150$ to $\sim 96$ min and remained unchanged for several batches. Then, strain LF1 was selected from several isolates due to its faster growth on xylose (Fig. 1b). All the strains used in this study are listed in Table 1. 
Table 2 The concentrations of monosaccharides and inhibitors in SECS liquor and different hydrolysates

\begin{tabular}{|c|c|c|c|}
\hline & SECS liquor & SECS hydrolysate $(\mathrm{Hy} 1)^{a}$ & SPPR hydrolysate (Hy2) \\
\hline \multicolumn{4}{|l|}{ Main monosaccharides $\left(\mathrm{g} \mathrm{L}^{-1}\right)$} \\
\hline Glucose & $9.87 \pm 0.07$ & $86.60 \pm 0.160$ & $54.94 \pm 0.50$ \\
\hline Xylose & $36.54 \pm 0.28$ & $39.09 \pm 0.06$ & $23.79 \pm 0.19$ \\
\hline Solubilized lignin & $3.24 \pm 0.01$ & $4.13 \pm 0.02$ & - \\
\hline \multicolumn{4}{|l|}{ Main inhibitors } \\
\hline \multicolumn{4}{|l|}{ Weak acids $\left(\mathrm{g} \mathrm{L}^{-1}\right)$} \\
\hline Formic acid & ND & ND & ND \\
\hline Acetic acid & $4.77 \pm 0.14$ & $4.52 \pm 0.01$ & $0.00 \pm 0.00$ \\
\hline Levulinic acid & ND & ND & ND \\
\hline \multicolumn{4}{|l|}{ Furan aldehydes $\left(\mathrm{g} \mathrm{L}^{-1}\right)$} \\
\hline Furfural & $0.37 \pm 0.01$ & $0.47 \pm 0.01$ & - \\
\hline HMF & $0.71 \pm 0.02$ & $0.66 \pm 0.03$ & - \\
\hline Total phenolics $\left(\mathrm{mmol} \mathrm{L}^{-1}\right)$ & $19.63 \pm 0.29$ & $26.68 \pm 0.61$ & - \\
\hline
\end{tabular}

Values are given as the averages and standard deviations of three independent measurements

a Hy1 refers to the hydrolysate from SECS supplied by Novozymes

b Hy2 refers to the hydrolysate from SPPR supplied by the Shandong Tranlin Group

\section{Combinatorial strategy improved xylose assimilation and strain tolerance for lignocellulosic hydrolysates}

After multiple rational molecular modifications, BSN3 could grow on xylose and convert xylose to ethanol, but its efficiency was not high, similar to previous reports (Demeke et al. 2013; Diao et al. 2013). However, the xylose-evolved strain XH7 was much improved. Compared to BSN3, XH7 exhibited better fermentation performance, especially with respect to xylose consumption and ethanol yield, when the carbon source was either xylose alone or a glucose-xylose mixture (Table 3, Line 1 vs. 2 , Line 3 vs. 4). When xylose was the sole carbon source, XH7 consumed all of the $40 \mathrm{~g} \mathrm{~L}^{-1}$ xylose in $26 \mathrm{~h}$, resulting in an ethanol yield of $0.480 \mathrm{~g} \mathrm{~g}^{-1}$ consumed sugar (Table 3, Line 2), which is more than $94 \%$ of the theoretical yield. This result was even somewhat higher than the corresponding values in the mixed-sugar fermentation (Table 3, Line 4). In contrast, the biomass yield of XH7 was lower than that of BSN3 (Table 3, Line 1 vs. 2 , Line 3 vs. 4). These results indicate that the majority of the consumed xylose in XH7 was used to produce ethanol rather than to maintain cell growth as in BSN3.

However, the xylose utilization performance of $\mathrm{XH7}$ worsened in the presence of the inhibitors contained in the SECS hydrolysate (the concentrations of its main components are shown in Table 2). When $0.5 \mathrm{~g} \mathrm{DCW}$ (dry cell weight) $\mathrm{L}^{-1}$ initial cells, which was the same inoculation used in the inhibitor-free medium, were inoculated in YP supplemented with the SECS hydrolysate, XH7 consumed $23.16 \mathrm{~g} \mathrm{~L}^{-1}$ xylose (Fig. 2a; Table 3, Line 5). Because of the costs of industrialization, a cheap nitrogen source, urea, was also tested with initial inoculum sizes of 0.5 or $1.5 \mathrm{~g} \mathrm{DCW} \mathrm{L}^{-1}$; XH7 consumed 18.74 and $34.16 \mathrm{~g} \mathrm{~L}^{-1}$ xylose, respectively (Fig. 2b, c; Table 3, Lines 6, 7). Although richer nutrients and more initial cells improved the fermentation of the hydrolysate, strain performance was still a distinct disadvantage. These results indicate that cell growth was inhibited by the inhibitors derived from the pretreatment and hydrolysis of the lignocellulosic materials.

After an extensive adaptive evolution performed in the presence of inhibitors, the evolved strain XHR11 exhibited better growth in the SECS hydrolysate supplemented with urea. The maximum biomass reached $4.62 \mathrm{~g} \mathrm{DCW} \mathrm{L}^{-1}$, which was more than XH7 achieved (3.77 $\mathrm{g} \mathrm{DCW} \mathrm{L}^{-1}$ ) (Fig. 2c, d). However, XHR11 consumed less xylose either in the SECS hydrolysate (Fig. 2c, d; Table 3, Line 7 vs. 8 ) or in the inhibitors-free medium (Fig. 3a vs. c, b vs. d; Table 3, Line 9 vs. 10, Line 12 vs. 13); even glucose utilization was slightly decreased (Fig. 3b, d). These results indicated that adaptive evolution effectively improved the tolerance of the strain to inhibitors but affected the metabolic capacities for these sugars, probably due to some unknown changes caused by toxic stress.

In XHR11, the heterologous expression of the transporter mutant MGT05196 ${ }^{\mathrm{N} 360 \mathrm{~F}}$, which encodes a xylose-specific, glucose-insensitive transporter (Wang et al. 2015), together with adaptive evolution on xylose, enhanced xylose consumption by $55.5 \%$ in the resulting strain, LF1 $(P<0.05)$ (Fig. 4a). In other words, the xylose metabolic capacity was recovered and the key fermentation parameters were even better in LF1 than in XH7 under inhibitor-free conditions (Table 3, Line 11 vs. 9 


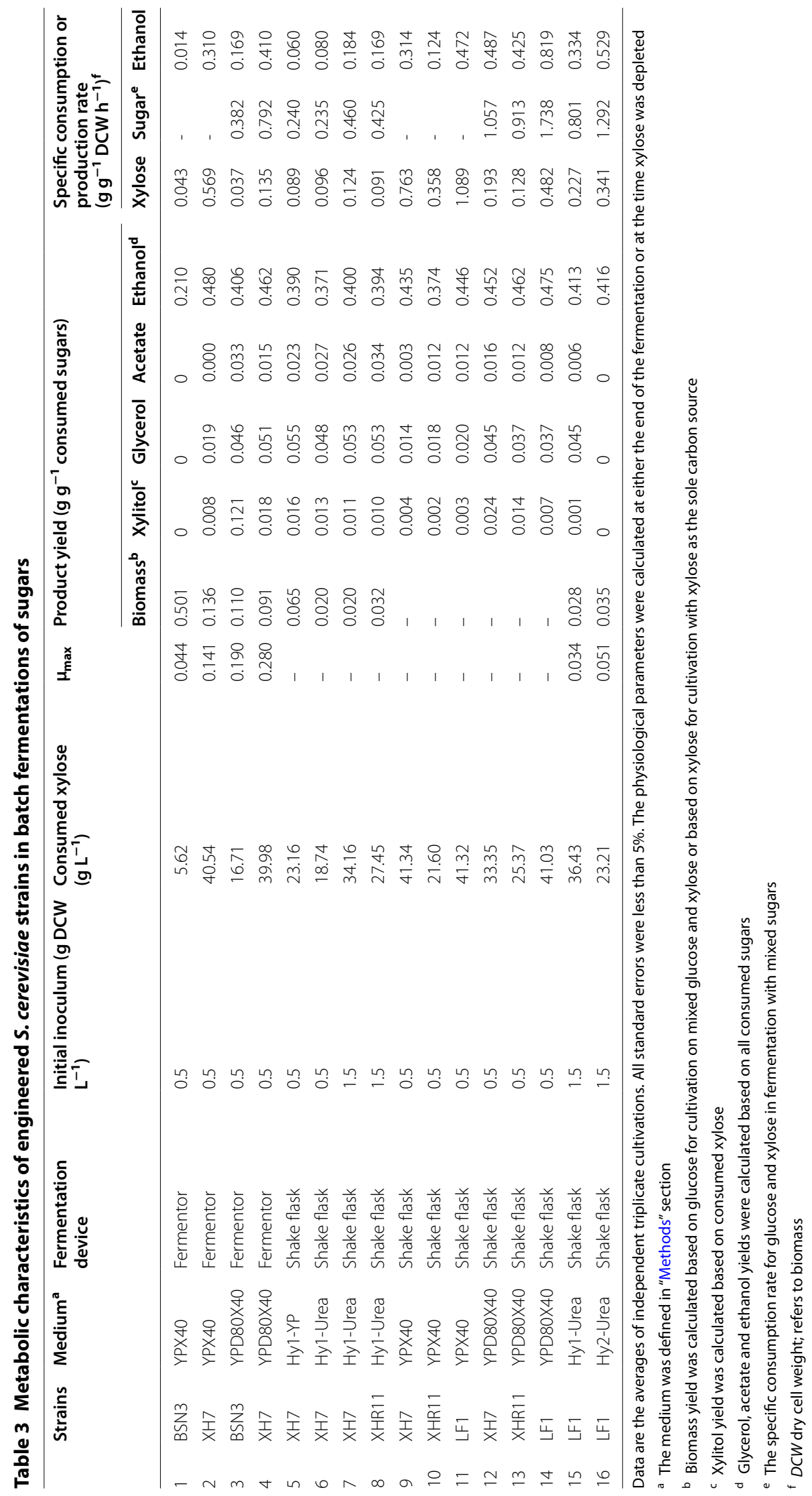



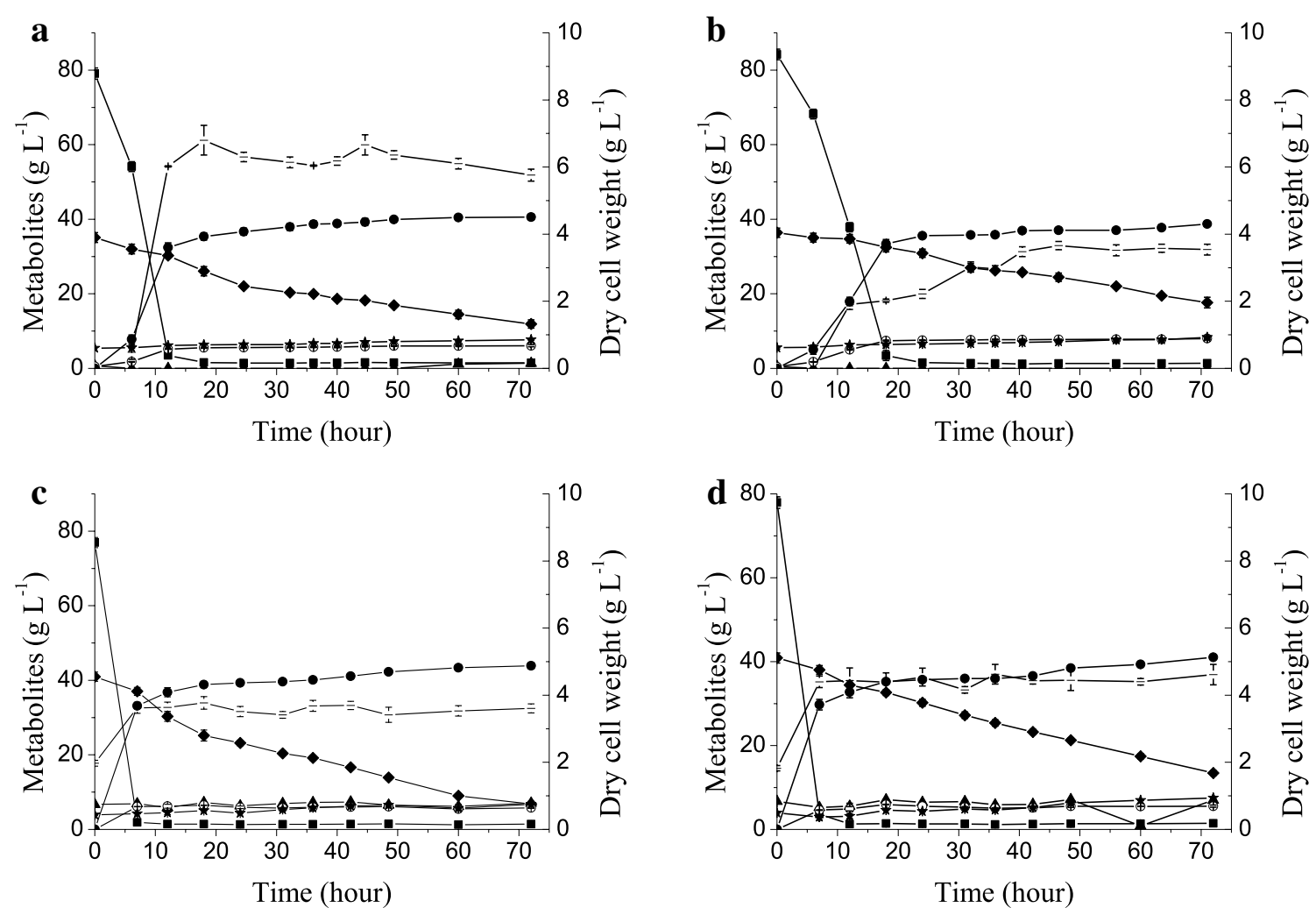

Fig. 2 Fermentation characteristics of strains in SECS hydrolysate with different sources of nitrogen and initial inoculum sizes. The experiments were performed in triplicate in SECS hydrolysates supplied by Novozymes (Table 2). Cells were cultured at $30^{\circ} \mathrm{C}$ in a shake flask with a rubber stopper and agitation at $200 \mathrm{rpm}$. Strain XH7 (Fig. 1b; Table 1) a with $0.5 \mathrm{~g} \mathrm{DCW} \mathrm{L}^{-1}$ initial biomass in YP (10 g L${ }^{-1}$ yeast extract and $20 \mathrm{~g} \mathrm{~L}^{-1}$ peptone); b with $0.5 \mathrm{~g} \mathrm{DCW} \mathrm{L}^{-1}$ initial biomass in $5 \mathrm{~g} \mathrm{~L}^{-1}$ urea; c with $1.5 \mathrm{~g} \mathrm{DCW} \mathrm{L}^{-1}$ initial biomass in $5 \mathrm{~g} \mathrm{~L}^{-1}$ urea; and $\mathbf{d}$ strain XHR11 with $1.5 \mathrm{~g} \mathrm{~L}^{-1}$ initial biomass in $5 \mathrm{~g} \mathrm{~L}^{-1}$ urea. Symbols: filled square glucose; filled diamond xylose; filled triangle xylitol; filled circle ethanol; open circle glycerol; filled star acetic acid; dash biomass (DCW dry cell weight)

and 10, Line 14 vs. 12 and 13; Fig. 3). When xylose was the sole carbon source, the specific xylose consumption rate of LF1 was $1.089 \mathrm{~g} \mathrm{~g}^{-1} \mathrm{~h}^{-1}$ with an ethanol yield of $0.446 \mathrm{~g} \mathrm{~g}^{-1}$ (Table 3, Line 11), which was greater than $87 \%$ of the theoretical yield. In a mixed glucose-xylose fermentation, the ethanol yield was $0.475 \mathrm{~g} \mathrm{~g}^{-1}$ sugars (Table 3, Line 14), which was greater than $93 \%$ of the theoretical yield. Moreover, $77.6 \%$ of xylose was consumed along with the glucose within $12 \mathrm{~h}$ in a glucose-xylose co-fermentation (Fig. 3f), which indicates a higher synchronization in sugar utilization. In conclusion, although LF1 retained the weak glucose utilization inherited from XHR11, its xylose metabolic capacity was rescued, and it obtained a high degree of synchronicity in glucose and xylose utilization (Fig. 3).

However, microorganisms with good fermentation performances in the presence of the inhibitors contained in lignocellulosic hydrolysates are candidates for industrial purposes. Therefore, the fermentation capacity of LF1 was tested with the following two different sources of

(See figure on next page)

Fig. 3 Oxygen-limited fermentation characteristics of strains in xylose and a glucose-xylose mixture in shake flasks. The experiments were performed in triplicate in YP $\left(10 \mathrm{~g} \mathrm{~L}^{-1}\right.$ yeast extract and $20 \mathrm{~g} \mathrm{~L}^{-1}$ peptone) with xylose (left) or a glucose-xylose mixture (right). Cells with $0.5 \mathrm{~g} \mathrm{DCW} \mathrm{L}{ }^{-1}$ initial biomass were cultured at $30^{\circ} \mathrm{C}$ in a shake flask with a rubber stopper and agitation at $200 \mathrm{rpm}$. Strains (Fig. 1b; Table 1): XH7 (a, b); XHR11 (c) d); LF1 (e, f). Symbols: filled square glucose; filled diamond xylose; filled triangle xylitol; filled circle ethanol; open circle glycerol; filled star acetic acid; dash biomass (DCW dry cell weight). $\mathbf{g}$ The specific xylose consumption rate of each strain. In xylose (blank columns), the rate was calculated based on the interval from the start to either xylose depletion $(\mathbf{a}, \mathbf{e})$ or the end of fermentation (c). In mixed sugars (shaded columns), the rate was calculated based on the interval from the glucose-depleted node (dot line) either to xylose depletion (f) or to the end of fermentation (b, d) 

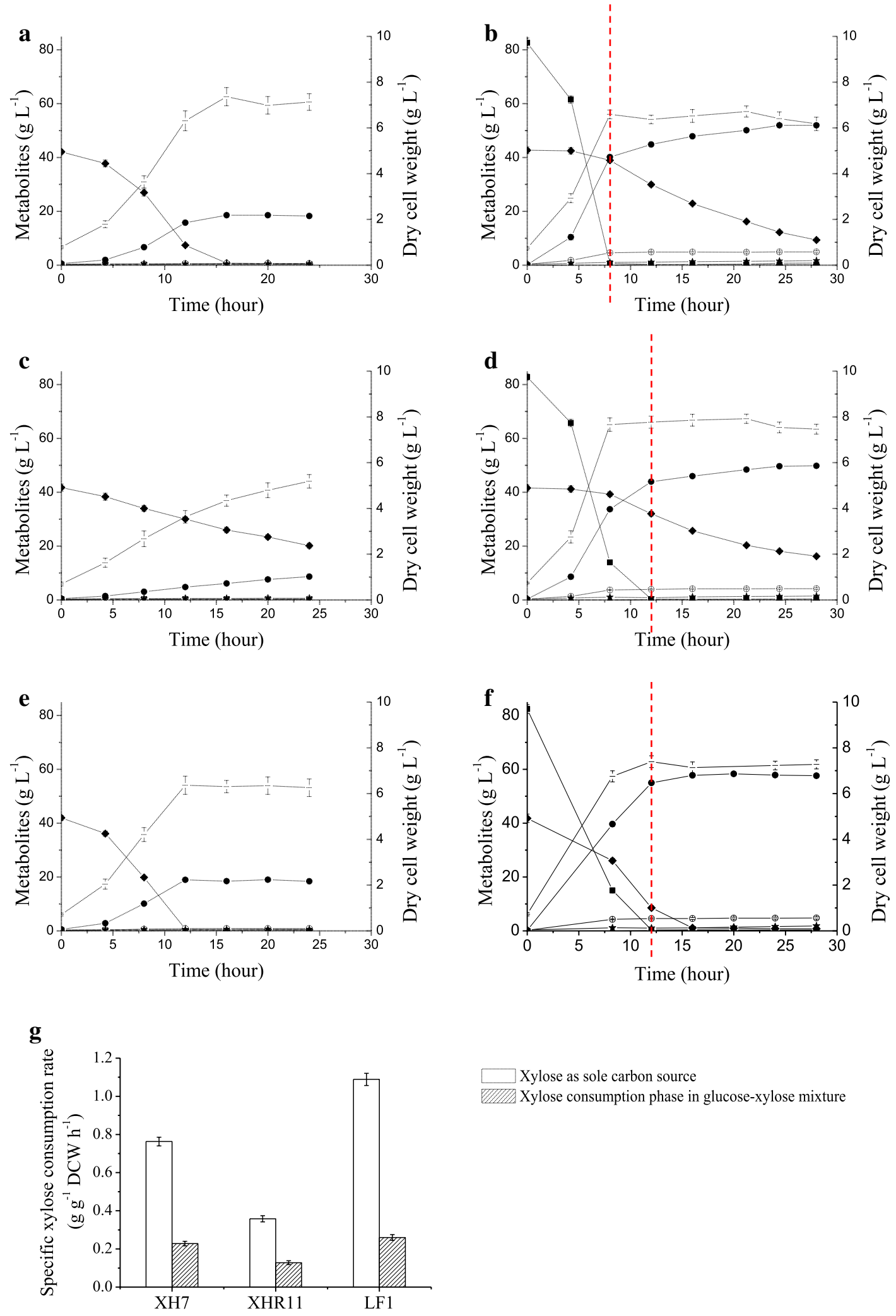

Xylose as sole carbon source
$\mathbb{W}$ Xylose consumption phase in glucose-xylose mixture 


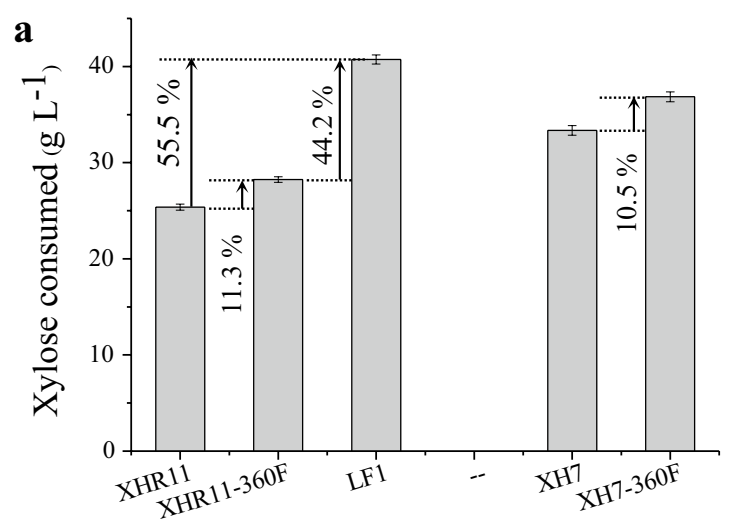

b

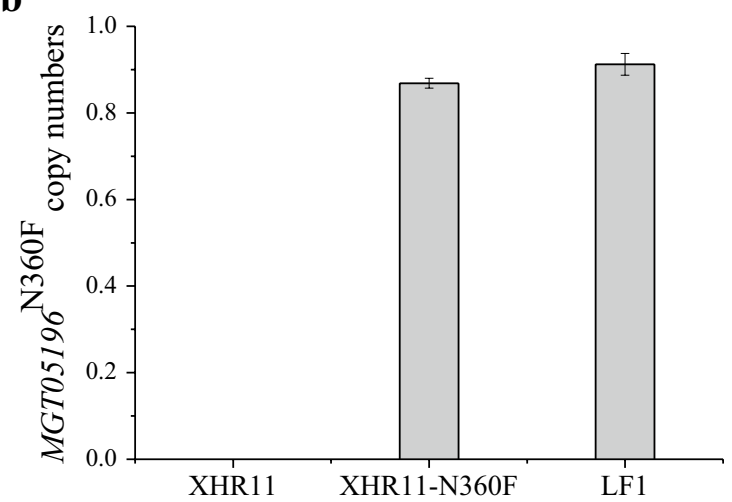

c

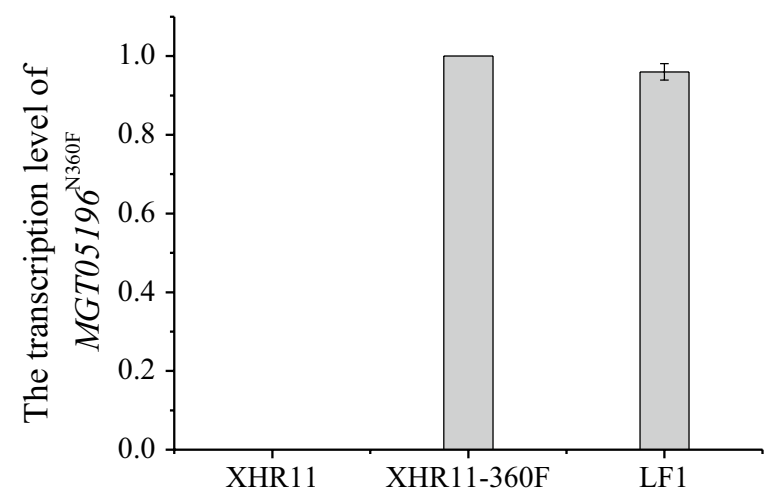

Fig. 4 The biography of the transporter mutant MGT05196 ${ }^{\mathrm{N} 360 \mathrm{~F}}$ in strains. Xylose consumption of strains harboring the xylose-specific, glucose-insensitive transporter encoded by the gene MGT05196 ${ }^{\text {N360F }}$ (Wang et al. 2015) in a glucose-xylose mixture (a); transporter gene copy numbers (b) and transcription levels (c). All experiments were performed in triplicate

lignocellulosic hydrolysates: SECS and SPPR (sulfite pretreatment papermaking residue) (Table 2; Fig. 5; Table 3, Lines 15, 16). LF1 consumed almost all the sugars in both of the hydrolysates, and both ethanol yields reached over $80.0 \%$ of the theoretical yield. In both cases, glucose was
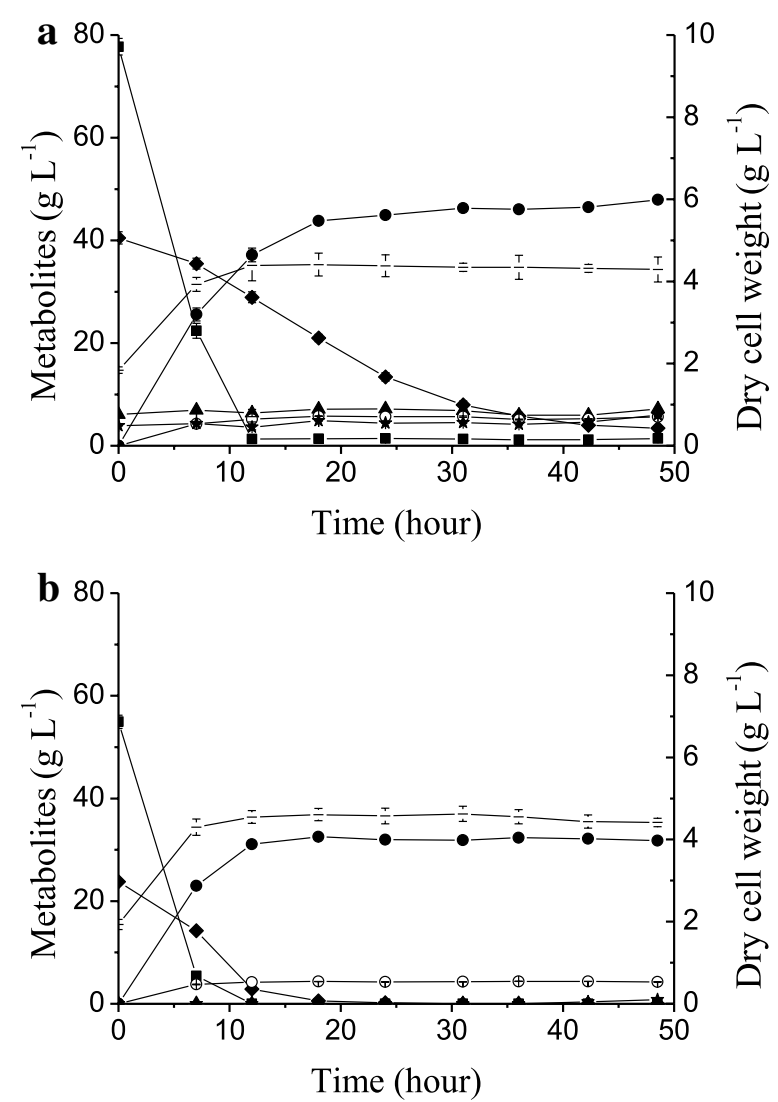

Fig. 5 Oxygen-limited fermentation characteristics of strain LF1 in different lignocellulosic hydrolysates. The experiments were performed in triplicate in SECS hydrolysates a supplied by Novozymes or SPPR hydrolysates $\mathbf{b}$ supplied by the Shandong Tranlin Group (Table 2). The cells were cultured at $30^{\circ} \mathrm{C}$ in a shake flask with a rubber stopper and agitation at $200 \mathrm{rpm}$. Symbols: filled square glucose; filled diamond xylose; filled triangle xylitol; filled circle ethanol; open circle glycerol; filled star acetic acid; dash biomass (DCW dry cell weight)

depleted within $12 \mathrm{~h}$. However, xylose consumption took longer in SECS (90\% xylose in $40 \mathrm{~h}$ ) than in SPPR (total xylose in $18 \mathrm{~h}$ ) (Fig. 5). Moreover, the biomass yield in SECS was lower $\left(0.034 \mathrm{~g} \mathrm{~g}^{-1}\right)$ than in SPPR $\left(0.057 \mathrm{~g} \mathrm{~g}^{-1}\right)$ (Table 3 , Lines 15,16 ). This result is probably due to the toxicity of the SECS hydrolysate, which is higher than that of SPPR (Table 2) and inhibited the cells growth; therefore, the specific xylose consumption and ethanol production rates were also lower (Table 3, Line 15 vs. 16). LF1 and XHR11 were similarly tolerant of the SECS hydrolysate, and both the specific xylose consumption and ethanol production rates were improved compared with those of XH7 (Table 3, Line 7). These results highlight the great potential of LF1 in the practical production of second-generation bioethanol. 


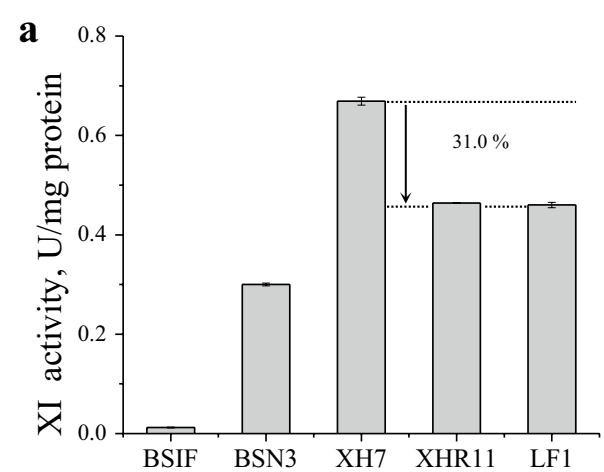

$\mathbf{b}$

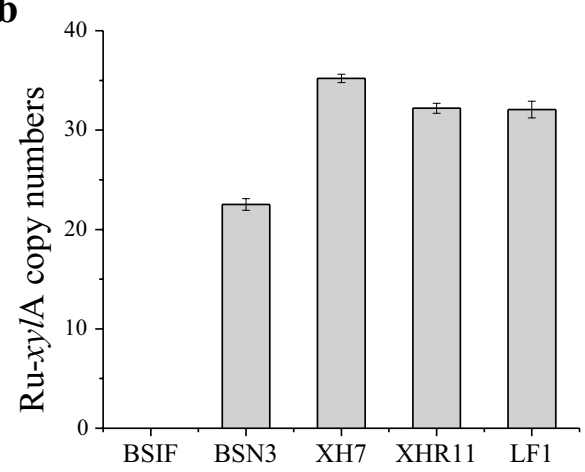

c

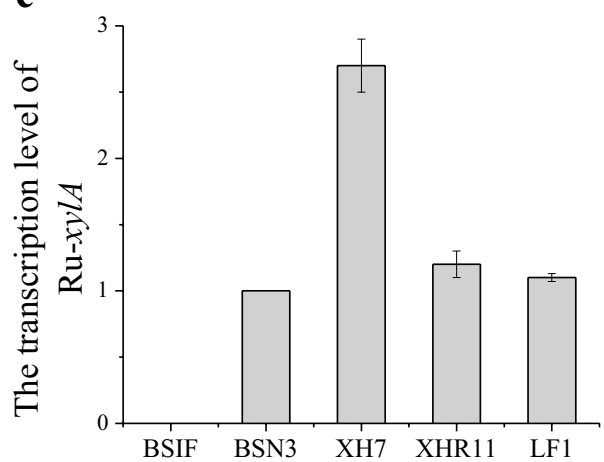

Fig. 6 The biography of xylose isomerase (XI) in each strain. Enzyme activities (a), copy numbers (b) and transcription levels (c) of the gene encoding Ru-xylA (Bao et al. 2013; Hou et al. 2016a). All experiments were performed in triplicate
The genetic basis of the efficient xylose metabolism of the evolved strains

As described above, a series of modified strains were derived from the robust diploid yeast (Fig. 1b), and they exhibited an alternation from increase to decrease in terms of xylose metabolic capacity. Therefore, the genetic changes responsible for the xylose assimilation phenotype were preliminarily analyzed.

The specific activity of xylose isomerase (XI), which is generally considered an important factor (Diao et al. 2013; Hou et al. 2016a), was boosted from $0.30 \mathrm{U} \mathrm{mg}^{-1}$ in BSN3 to $0.67 \mathrm{U} \mathrm{mg}^{-1}$ in XH7 (Fig. 6a). This improvement was due to the change of copy number of Ru-xylA in the genome, which increased from $22.52 \pm 0.58$ to $35.20 \pm 0.42$; therefore, the expression level of $\mathrm{Ru}-x y l \mathrm{~A}$ increased approximately threefold (Fig. 6b, c). A similar phenomenon was also described by Zhou et al. (2012). This increase was possibly due to chromosomal translocations (Pannunzio et al. 2012) and the increased activity of retrotransposons (Robberecht et al. 2013) during adaptive evolution. Unfortunately, inhibitor stress dropped the specific activity of XI by $\sim 31.0 \%$ in XHR11 $(P<0.05)$, an effect passed to LF1 (Fig. 6a). We speculated that this impact occurred at the transcriptional level because in comparison with XH7, the copy numbers of Ru-xylA in XHR11 and LF1 exhibited no significant difference, but the transcription levels of Ru$x y l A$ in these two strains declined significantly, almost to the level in BSN3 (Fig. 6b, c). Even so, the specific activities of xylose isomerase in XHR11 and LF1, which were both $\sim 0.46 \mathrm{U} \mathrm{mg}^{-1}$, were still higher than that in BSN3 (Fig. 6a).

The fold changes in the transcript levels of the endogenous genes XKS1, TAL1, TKL1, RKI1, and RPE1 are shown in Table 4. The XKS1 native promoter was replaced by a stronger in situ promoter, and extra copies of the other genes were integrated into the genome (Additional file 1: Fig. S1c, d); as expected, the genes were overexpressed in BSN3. After adaptive evolution

Table 4 The gene expression levels of the engineered strains

\begin{tabular}{|c|c|c|c|c|c|c|c|}
\hline & \multirow[t]{2}{*}{ Gene } & \multirow[t]{2}{*}{ Encoded protein } & \multicolumn{5}{|c|}{ Fold change (compared with the chassis strain BSIF) } \\
\hline & & & BSIF & BSN3 & $\mathrm{XH7}$ & XHR11 & LF1 \\
\hline 1 & XKS1 & Xylulokinase & 1 & $20.6 \pm 5.2$ & $22.0 \pm 1.6$ & $12.3 \pm 2.9$ & $21.5 \pm 0.5$ \\
\hline 2 & TAL1 & Transaldolase & 1 & $7.7 \pm 2.5$ & $10.0 \pm 2.0$ & $9.0 \pm 0.5$ & $9.4 \pm 0.3$ \\
\hline 3 & TKL1 & Transketolase & 1 & $7.3 \pm 1.8$ & $6.0 \pm 0.6$ & $4.9 \pm 0.3$ & $4.6 \pm 0.2$ \\
\hline 4 & RKI1 & Ribose 5-phosphate isomerase & 1 & $14.4 \pm 1.3$ & $238.8 \pm 15.3$ & $146.78 \pm 3.5$ & $144.5 \pm 0.6$ \\
\hline 5 & RPE1 & Ribulose 5-phosphate epimerase & 1 & $38.0 \pm 2.6$ & $51.9 \pm 3.6$ & $31.2 \pm 0.8$ & $30.0 \pm 0.4$ \\
\hline
\end{tabular}

Values are given as the averages and standard deviations of three independent measurements 
in xylose (Fig. 1b), the transcription levels of RKI1 and $R P E 1$ further rose from $14.4 \pm 1.3$ and $38.0 \pm 2.6$ to $238.8 \pm 15.3$ and $51.9 \pm 3.6$, respectively (in fold changes compared with the original levels in the parent). However, the transcription levels of XKS1, TAL1 and TKL1 were not significantly different in XH7 compared with those of BSN3. In contrast, evolution in the presence of inhibitors resulted in significantly lower transcription levels of RKI1 and RPE1 in XHR11, an effect that persisted in LF1. However, the expression level of XKS1 in LF1 ( $21.5 \pm 1.5$-fold higher than in BSIF) was restored to almost the same level as in XH7 (22.0 \pm 1.6 -fold higher than in BSIF) due to another round of evolution in the presence of xylose (Fig. 1b). Transaldolase (encoded by TAL1) is regarded as the primary rate-limiting step of xylose metabolism in engineered $S$. cerevisiae, and this limitation can be overcome either by overexpressing TAL1 or by indirectly upregulating it through the deletion of PHO13 (Xu et al. 2016). In all of the engineered strains in the present work (from BSN3 to LF1), we found that the transcription levels of TAL1 and TKL1 were relatively stable (Table 4, Lines 2,3 ), which may indicate their positive, conserved role in the xylose fermentation metabolic network (Walfridsson et al. 1997; Xu et al. 2016).

Two modifications contributed to the total $55.5 \%$ of xylose consumption increase exhibited by LF1 relative to XHR11. The expression of the glucose-insensitive, xylose-specific transporter Mgt05196p ${ }^{\mathrm{N} 360 \mathrm{~F}}$ (Wang et al. 2015 ) led directly to an $11.3 \%$ increase in the xylose consumption rate of XHR11 (for XH7, a similar increase of $10.5 \%$ was observed). The other $44.2 \%$ increase exhibited by LF1 was due to adaptive evolution on xylose (Fig. 4a). Because the copy number and transcription level of MGT05196 ${ }^{\mathrm{N} 360 \mathrm{~F}}$ remained nearly constant (Fig. 4b, c), and strains of XHR11 and XH7 without this transporter were also evolved at the same time but did not exhibit any enhancement in their xylose metabolic capacity in this round of evolution (data not shown), it is evident that this type of transporter was an important positive factor for improving xylose metabolism in S. cerevisiae. The transporter probably not only directly enhanced the absorption of xylose but also affected the overall evolutionary trend.

\section{Discussion}

Recently, strains of S. cerevisiae engineered for secondgeneration bioethanol production have been continuously improved, inching closer to industrialization. In general, multiple modifications have been used, including the rational establishment of a xylose metabolic pathway and non-rational adaptive evolution to improve xylose metabolic capacity and inhibitor tolerance (Kim et al. 2013; Ko et al. 2016; Kuyper et al. 2005a; Peng et al. 2012;
Van Vleet and Jeffries 2009). Moreover, using robust yeast strains as chassis cells has also proved to be an effective strategy (Demeke et al. 2013; Diao et al. 2013; Li et al. 2015). In the present work, based on our previous study, the $S$. cerevisiae wild-type diploid strain BSIF, which is highly robust and possesses a good genetic background for xylose metabolism, was used as the chassis cell ( $\mathrm{Li}$ et al. 2015). The following two key novel elements were introduced into the chassis cell: MGT05196 ${ }^{\mathrm{N} 360 \mathrm{~F}}$, which encodes a xylose-specific, glucose-insensitive transporter derived from the $M$. guilliermondii transporter gene MGT05196 (Wang et al. 2015), and Ru-xylA, which encodes a xylose isomerase (XI) with higher activity in $S$. cerevisiae and was derived from a screen of a bovine rumen metagenomic library (Bao et al. 2013). Another highlight in strain construction was the use of multiple adaptive evolutions under xylose and inhibitor stresses.

Overall, these modifications resulted in strain LF1, which has an excellent xylose fermentation capacity in media prepared from both sugars (Fig. 3) and lignocellulosic hydrolysates (Fig. 5). When xylose was the sole carbon source, LF1 consumed all of the $40 \mathrm{~g} \mathrm{~L}^{-1}$ xylose in $12 \mathrm{~h}$ with initial inoculum size of $0.5 \mathrm{~g} \mathrm{DCW} \mathrm{L}^{-1}$, and resulted in an ethanol yield of $0.446 \mathrm{~g} \mathrm{~g}^{-1}$. In contrast, CIBTS0735, a similarly engineered strain harboring the xylose isomerase gene xylA from Piromyces and the transporter gene GXF1 from Candida intermedia (Diao et al. 2013), required $16 \mathrm{~h}$ to consume nearly the same amount of xylose with initial inoculum size of $0.63 \mathrm{~g} \mathrm{DCW} \mathrm{L}^{-1}$, and resulted in a lower ethanol yield of $0.412 \mathrm{~g} \mathrm{~g}^{-1}$. Moreover, GS1.11-26, another similarly engineered strain that harbors the xylose isomerase gene $x y l A$ from Clostridium phytofermentans and overexpresses the endogenous transporter gene HXT7 (Demeke et al. 2013), resulted in a slightly higher ethanol yield of $0.460 \mathrm{~g} \mathrm{~g}^{-1}$ but also required $17 \mathrm{~h}$ to ferment less xylose $\left(35 \mathrm{~g} \mathrm{~L}^{-1}\right)$ with a larger initial inoculum size $\left(1.3 \mathrm{~g} \mathrm{DCW} \mathrm{L}^{-1}\right)$. In a glucose-xylose mixture, LF1 consumed $80 \mathrm{~g} \mathrm{~L}^{-1}$ glucose and $40 \mathrm{~g} \mathrm{~L}^{-1}$ xylose in $16 \mathrm{~h}$ with an ethanol yield of $0.475 \mathrm{~g} \mathrm{~g}^{-1}$, which was greater than $93 \%$ of the theoretical yield. In contrast, the corresponding values for CIBTS0735 (Diao et al. 2013) were $20 \mathrm{~h}$ and an ethanol yield of $0.454 \mathrm{~g} \mathrm{~g}^{-1}$ in a fermentation with the same amount of mixed sugars. Additionally, GS1.11-26 (Demeke et al. 2013) required only $13 \mathrm{~h}$ to produce an ethanol yield of $0.46 \mathrm{~g} \mathrm{~g}^{-1}$ but fermented less sugar ( $36 \mathrm{~g} \mathrm{~L}^{-1}$ glucose and $37 \mathrm{~g} \mathrm{~L}^{-1}$ xylose) with a larger initial inoculum size $\left(1.3 \mathrm{~g} \mathrm{DCW} \mathrm{L}^{-1}\right)$ compared with the 0.5 and $0.63 \mathrm{~g} \mathrm{DCW} \mathrm{L}^{-1}$ of LF1 used in the present work (Fig. 5) and CIBTS0735 (Diao et al. 2013), respectively. Other similarly engineered strains did not show improvement in key fermentation parameters, as discussed above (Ko et al. 2016; Romaní et al. 2015; Smith 
et al. 2014). Additionally, LF1 also performed well in the fermentation of two types of lignocellulosic hydrolysates, even when supplied with the simple nitrogen source urea rather than yeast extract and peptone (Fig. 5). Moreover, LF1 prominently displayed highly synchronized glucose and xylose utilization not only in a mixture of the sugars (with a utilization of $77.6 \%$ xylose and glucose depletion at $12 \mathrm{~h}$ ) but also in SPPR hydrolysate, and ethanol production in LF1 peaked quickly (Fig. 3d vs. f, 5). This characteristic is a significant advantage in second-generation bioethanol production because it will save fermentation time, reduce staff input, and so on.

During approximately 40 years of metabolic engineering in yeast to co-ferment xylose and glucose, researchers have gradually realized that it is easier to establish a xylose metabolic pathway than to improve the efficiency of xylose fermentation and glucose-xylose co-fermentation. Although much research toward this goal has been performed, key factors in this strategy remain unknown. Therefore, non-rational adaptive evolution is generally used for strain engineering (Almeida et al. 2007; Heer and Sauer 2008b; Kuyper et al. 2005b). In the present work, we also focused on the strain breeding, therefore, the contribution for 'key factors' exploration maybe not enough.

Increasing the activity of xylose isomerase (XI), which isomerizes xylose directly to xylulose, is considered a good basis for establishing a xylose metabolic pathway in S. cerevisiae (Brat et al. 2009; Kuyper et al. 2003; Madhavan et al. 2009; Walfridsson et al. 1996; Zhou et al. 2012). The specific activity of XI in LF1 $\left(0.46 \mathrm{U} \mathrm{mg}^{-1}\right)$ was $231.0 \%$ lower than in XH7 (which exhibited the highest activity of the strains in this study, $0.67 \mathrm{U} \mathrm{mg}^{-1}$ ) but was higher than in BSN3 $\left(0.30 \mathrm{U} \mathrm{mg}^{-1}\right)$ (Fig. 6a). However, the xylose fermentation capacity of LF1 was much improved compared with that of XH7 and BSN3 (Fig. 3; Table 3). This result implied that maintaining a moderate XI activity has a positive effect on the enhancement of xylose fermentation. The overexpression of Xks1p and four enzymes in the non-oxidative PPP is a common strategy to strengthen xylose metabolism (Bamba et al. 2016; Kuyper et al. 2005a; Peng et al. 2012; Sharma et al. 2016). Previous reports have shown that moderate, rather than extremely high, Xks1p activity is more beneficial for growth and ethanol production from xylose because this enzyme catalyzes an ATP-consuming reaction (Jin et al. 2003; Peng et al. 2011). In the present work (Table 4), the Xks1p (encoded by XKS1) expression level fluctuated noticeably. However, the expression level remained relatively high and constant in both improved xylose-fermenting strains, XH7 and LF1. Therefore, such a Xks1p expression level is apparently suitable for xylose metabolism. However, BSN3 also exhibited a similar
Xks1p expression level (Table 4), even though this strain has not undergone any adaptive evolution and utilizes xylose poorly (Table 3 , Line 1 ). Obviously, then, a suitable Xks1p activity is not the sole factor governing xylose metabolic capacity. Except for that of ribose 5-phosphate isomerase (encoded by RKI1), the expression levels of the enzymes in the non-oxidative PPP showed no significant change (Table 4). After the first round of adaptive evolution under xylose stress, the expression of RKI1 was upregulated from $14.4 \pm 1.3$ in BSN3 to $238.8 \pm 15.3$ in XH7 (in fold change relative to the original chassis, BSIF). Then, inhibitor stress dropped its expression to $146.78 \pm 3.5$ in XHR11 and remained at $144.5 \pm 0.6$ in LF1 (Table 4). As discussed above, XH7 and LF1 (but not BSN3 and XHR11) showed improved xylose fermentation, which indicates that ribose 5-phosphate isomerase, rather than the other three enzymes in the non-oxidative PPP, are important for xylose fermentation, as well as other key factors.

The transport issue is another limiting factor for xylose fermentation. Mgt05196p ${ }^{\mathrm{N} 360 \mathrm{~F}}$, a xylose-specific transporter with no glucose inhibition (Wang et al. 2015), was therefore introduced into the chassis cells. As expected, the transporter enhanced xylose utilization to some extent by simple expression. Moreover, after the Mgt$05196 \mathrm{p}^{\mathrm{N} 360 \mathrm{~F}}$-containing strain was evolved in the presence of xylose (Fig. 1b), glucose and xylose utilization efficiency and synchronicity improved (Fig. 3; Table 3). Strain XHR11, which lacked this transporter, did not show any change in its xylose metabolic capacity during the same adaptive evolution, and the copy numbers and transcription levels of MGT05196 ${ }^{\mathrm{N} 360 \mathrm{~F}}$ remained constant in XHR11-360F and LF1. Therefore, we deduced that Mgt05196 $\mathrm{p}^{\mathrm{N} 360 \mathrm{~F}}$ absorbed significantly more intracellular xylose, which resulted in stronger xylose stress tolerance in these cells and drove evolution beneficially toward xylose metabolism. Therefore, Xks1p expression recovered in LF1 relative to its parent. However, ribose 5 -phosphate isomerase expression did not recover in LF1 (Table 4), which indicates that non-rational adaptive evolution led to random changes in other genes, and the key factors contributing to xylose metabolism must be numerous. An exploration of these unknown factors and their function via inverse metabolic engineering would be a significant undertaking. S. cerevisiae maintains high levels of glycolysis and PPP enzymes when glucose is present, and it shifts to respiratory metabolism after glucose is exhausted (Salusjarvi et al. 2008). Because xylose is metabolized through the PPP and glycolysis, its utilization will obviously drop as well. Furthermore, in respiratory metabolism, pyruvate prefers to enter the tricarboxylic acid cycle instead of producing ethanol. Therefore, using a specific transporter to facilitate the 
synchronized co-fermentation of glucose and xylose is beneficial for their co-utilization.

It was observed that xylose consumption was inhibited by the presence of glucose; therefore, the specific xylose consumption rates in the sugar mixture were lower than when xylose was the sole carbon source (Table 3, line 9 vs. 12,10 vs. 13, 11 vs. 14) (Demeke et al. 2013; Diao et al. 2013; Peng et al. 2012; Shen et al. 2012), However, the same parameter was still kept lower (Fig. $3 \mathrm{~g}$ ) in the xylose consumption phase (Hou et al. 2009b) after the depletion of glucose from the sugar mixture. We defined such a phenotype-the continued impact of glucose on xylose metabolism after glucose depletion-as the "postglucose effect" in the present work, which is an underappreciated phenomenon frequently evident in data shown in previous publications (Demeke et al. 2013; Diao et al. 2013; Peng et al. 2012; Shen et al. 2012). Exploration of the mechanisms underlying the post-glucose effect and the discovery of elements to overcome this phenotype will be the focus of future research.

\section{Conclusions}

In the present work, two novel proprietary heterologous genes (MGT05196 ${ }^{\mathrm{N} 360 \mathrm{~F}}$ and $\left.\mathrm{Ru}-x y l A\right)$ were combined with other multiple genetic modifications and three rounds of adaptive evolution to engineer the diploid $S$. cerevisiae chassis strain BSIF. The final resulting strain of this effort, LF1, consumed all xylose $\left(40 \mathrm{~g} \mathrm{~L}^{-1}\right)$ and glucose $\left(80 \mathrm{~g} \mathrm{~L}^{-1}\right)$ in $16 \mathrm{~h}$ with an ethanol yield that was over 93\% of the theoretical yield. LF1 also performed well in lignocellulosic hydrolysates, with ethanol yields of over $80.0 \%$ of the theoretical yields. Moreover, LF1 exhibited highly synchronous utilization of glucose and xylose. These results highlight the great potential for the practical use of LF1 in the production of second-generation bioethanol. Despite the directed genetic changes detailed in this work, some unknown factors derived from adaptive evolution were also responsible for the superior fermentation performance of LF1. We also outlined the "post-glucose effect" phenomenon. An exploration of its underlying mechanisms remains key.

\section{Methods \\ Media}

In the present work, YP was composed of $10 \mathrm{~g} \mathrm{~L}^{-1}$ yeast extract and $20 \mathrm{~g} \mathrm{~L}^{-1}$ peptone. The YPD and YPX were composed of YP amended with glucose and xylose, respectively, in varying concentrations $\left(\mathrm{g} \mathrm{L}^{-1}\right)$. For example, YPX40 indicated that $40 \mathrm{~g} \mathrm{~L}^{-1}$ xylose was added to YP. Hy1 and Hy2 refer to the hydrolysates from SECS supplied by Novozymes and SPPR supplied by the Shandong Tranlin Group, respectively. The main components of both hydrolysates are listed in Table 2. Hy1(2)-YP was a mixture of the hydrolysate Hy1 with YP. Hy1(2)-Urea included an additional $5 \mathrm{~g} \mathrm{~L}^{-1}$ urea. SECS liquor referred to the liquid fraction of the steam-exploding corn stover without enzymolysis, which therefore contained less glucose (Table 2).

\section{Plasmid construction}

The chassis cell BSIF was diploid; therefore, to destroy two alleles of $\mathrm{PHO13}$, which would benefit xylose metabolism (Bamba et al. 2016; Lee et al. 2014; Shen et al. 2012; Van Vleet et al. 2008), two plasmids were assembled in the plasmid pUC19 as follows: pXIP1/2 (Additional file 1: Fig. S2a) containing two pairs of $P H O 13$-targeted recombinant arms, $P H O 13-$ RA1 vs. PHO13- RA2 and PHO13- RA1 vs. PHO13- RA3. Three tandem TEF1pRu-xylA-PGK1t cassettes, amplified from the plasmid pJX7 (Hou et al. 2014), and the loxP-KanMX4-loxP cassette, amplified from the plasmid pUG6 (Güldener et al. 1996; Peng et al. 2012), were also ligated into the plasmid. Given that the multiple repeats of the $\delta$-sequence in the chromosome could lead to multiple integrated copies of Ru-xylA in the genome (Cho et al. 1999; Yamada et al. 2010), a new pair of $\delta$-targeted recombinant arms, $\delta$-RA1 and $\delta-R A 2$, were introduced into pXIP1 instead of the $P H O 13$-targeted recombinant arms, resulting in pXI $\delta$ (Additional file 1: Fig. S2b). Similarly, inactivating the two alleles of GRE3 should also benefit xylose metabolism (Kuyper et al. 2005a). The plasmids pJPPP3 (Peng et al. 2012) (which contains individual expression cassettes for four non-oxidative PPP genes and a pair of GRE3-targeted recombinant arms, GRE3-RA1/AR2) and pJPPP4 (which was constructed by replacing the GRE3-RA2 fragment of pJPPP3 with GRE3-RA3) (Additional file 1: Fig. S2c) were used for this aim.

The specific transporter gene MGT05196 ${ }^{\mathrm{N} 360 \mathrm{~F}}$ (Wang et al. 2015) was inserted into another region of the GRE3 locus. To achieve this aim, a new pair of GRE3-targeted recombinant arms, GRE3-RA4/AR5, together with the transporter expression cassette TDH3p-MGT05196 ${ }^{\mathrm{N} 360 \mathrm{~F}}$ CYC1t and the selectable marker loxP-KanMX4-loxP, were ligated into pUC19. Additionally, to heighten expression, a fragment including three tandem sequences of the upstream activating sequence $\mathrm{UAS}_{\mathrm{CLB}}$ (Blazeck et al. 2012) was also ligated in front of the promoter TDH3p. The resulting plasmid, pUC-N360F, is shown in Additional file 1: Fig. S2d.

The relative positions of the introduced gene loci are shown in Additional file 1: Fig. S1. All of the plasmids and primers (with their relevant restriction enzyme sites) used in the present work are listed in Table 1 and Additional file 1: Table S1. respectively. 


\section{Strain construction}

All S. cerevisiae strains used in this work are listed in Table 1. The strain parentage is shown in Fig. 1b, and diagrams of the relative locations of each genetic manipulation are detailed in Additional file 1: Fig. S1.

Use of the Cre-loxP recombination system, which allows repeated use of a selection marker (Güldener et al. 1996), facilitated construction of the wild-type chassis cell. Accordingly, a new plasmid, YEp-CH, was constructed by the ligation of two fragments, an inducible GAL1p-controlled CreA recombinase expression cassette and a dominant hygromycin resistance gene expression cassette, into YEp24. The integration of each fragment into the genome involved several operational steps. The chassis cell was transformed with a loxP-KanMX4-loxPcontaining fragment and grown on YPD20 agar plates supplemented with G418 (400 $\left.\mathrm{mg} \mathrm{L}^{-1}\right)$. After evaluation and verification, the best-growing colony was then transformed with YEp-CH and grown on YPD20 agar plates supplemented with hygromycin $\left(200 \mathrm{mg} \mathrm{L}^{-1}\right)$. Then, the transformant was cultured in YP supplemented with galactose $\left(20 \mathrm{~g} \mathrm{~L}^{-1}\right)$ to induce the expression of the CreA recombinase and remove the KanMX4 cassette. Finally, the YEp-CH plasmid was lost on YPD20 without hygromycin selection. Such steps were cycled (Fig. 1b) in the wild-type chassis cell BSIF (Li et al. 2015).

The loxP-KanMX4-loxP-containing integration fragments were obtained in a different way. The Ru-xylA segments were recovered from $\mathrm{pXIP} 1 / 2$ and $\mathrm{pXI} \delta$ double-digested with EcoRI/SphI. The four genes in the PPP segments were recovered from $\mathrm{pJPPP} 3 / 4$ digested with SmiI. The MGT05196 ${ }^{\mathrm{N} 360 \mathrm{~F}}$ segments were linearized from pUC-N360F digested with SmiI. The TEF1p segments with two pairs of XKS1-targeted recombinant arms, XKS1-RA1/XKS1-RA3 and XKS1-RA2/XKS1-RA3, upstream of $X K S 1$ were amplified by overlap PCR, which was used to moderately strengthen the expression of XKS1 (Peng et al. 2011) by replacing its native promoter with a stronger one in two alleles (Additional file 1: Fig. S1c).

\section{Adaptive evolution}

Adaptive evolution was performed under either xylose or inhibitor stress. The cells were cultured at $30{ }^{\circ} \mathrm{C}$ and $200 \mathrm{rpm}$ in cotton-plugged $250-\mathrm{mL}$ shake flasks containing $50 \mathrm{~mL}$ YPX40 or SECS liquor with YP (pH 6.0), respectively. Cell growth was monitored by measuring the $\mathrm{OD}_{600}$ (optical density at $600 \mathrm{~nm}$ ). Once the stationary phase was reached, a new batch was started by transferring the culture into fresh medium with an initial $\mathrm{OD}_{600}$ of 0.5. Evolution was continued until the biomass doubling time $(T)$ did not shorten significantly. The biomass doubling time $T$ was calculated from $\mathrm{OD}_{600}$ during the exponential growth phase using the following equation, as described previously (Peng et al. 2012):

$$
T=\frac{t_{2}-t_{1}}{\log _{2}\left(\mathrm{OD}_{2} / \mathrm{OD}_{1}\right)}
$$

Dozens of colonies were isolated from the evolved strain suspension. Evaluations were performed under the same stress using the BioScreen system (Oy Growth Curves Ab Ltd, Helsinki, Finland) and further verified in shake flasks. Then, the single colony that grew fastest was selected for further use.

\section{Fermentation}

The batch fermentations were performed in either a 1.4-L fermenter with a $1000 \mathrm{~mL}$ working volume (Infors AG, Switzerland) or in $250-\mathrm{mL}$ shake flasks with a $50-\mathrm{mL}$ working volume. The different media described above were used as needed. The fermentations were performed at $30{ }^{\circ} \mathrm{C}$ and $200 \mathrm{rpm}$ agitation rate, with other parameters of either $0.04 \mathrm{vvm}$ ventilation (the oxygen-limited condition) (Zhang et al. 2010), pH 5.5 in the fermenters, or an initial $\mathrm{pH}$ of 6 in the shake flasks with a rubber stopper plug in a syringe needle (the oxygen-limited condition) (Walfridsson et al. 1996). Overnight cultures of a single colony were transferred to $100 \mathrm{~mL}$ YPD20 in 250$\mathrm{mL}$ shake flasks at an initial $\mathrm{OD}_{600}$ of 0.2 and incubated at $30{ }^{\circ} \mathrm{C}$ for another $12 \mathrm{~h}$ for inoculations ( $\mathrm{Li}$ et al. 2015). The data from the independent triplicate cultivations were compared using Student's $t$-test whenever indicated. A $P<0.05$ was considered statistically significant.

\section{Compounds Analysis and Calculation}

Biomass was determined by measuring $\mathrm{OD}_{600}$ (Eppendorf AG, 22331, Hamburg, Germany) and DCW. Different strains exhibited different coefficients between $\mathrm{OD}_{600}$ and DCW (data not shown). The maximum growth rates $\left(\mu_{\max }\right)$ are the linear regression coefficients of the $\ln \left(\mathrm{OD}_{600}\right)$ versus time during the exponential growth phase.

The concentrations of glucose, xylose, xylitol, glycerol, acetate, and ethanol were determined by HPLC (Shimadzu, Japan) with a BIO-RAD Aminex HPX-87H ion exclusion column $(300 \times 7.8 \mathrm{~mm})$ as previously described (Diao et al. 2013; Hou et al. 2016b; Peng et al. 2012). The mobile phase was $5 \mathrm{mmol} \mathrm{L}^{-1} \mathrm{H}_{2} \mathrm{SO}_{4}$ with a flow rate of $0.6 \mathrm{~mL} \mathrm{~min}^{-1}$. The temperature of the column oven was $45^{\circ} \mathrm{C}$. The specific consumption or production rates of xylose, xylitol, glycerol, acetate, and ethanol were calculated as previously described (Peng et al. 2012).

The monosaccharides, weak acid, furfural and HMF in the hydrolysates were measured using an HPX-87H column as described above ( $\mathrm{Li}$ et al. 2015). The total phenolics were determined using the Folin phenol method, 
and vanillin was used to prepare the standard curve (Singleton et al. 1999). Solubilized lignin was determined by measuring the absorbance at $320 \mathrm{~nm}$ (Li et al. 2015; Tan et al. 2013).

\section{Measurement of enzyme activities}

Overnight cultures were transferred into fresh YPD20 medium with 0.2 initial $\mathrm{OD}_{600}$ and cultured at $30{ }^{\circ} \mathrm{C}$. The cells were harvested at $\mathrm{OD}_{600} 4.0$ and washed twice with sterile water and resuspended in $100 \mathrm{mmol} \mathrm{L}^{-1}$ Tris- $\mathrm{HCl}(\mathrm{pH}$ 7.5) with a proteinase inhibitor cocktail (for fungal/yeast cells; Sangon Biotech Co., Ltd., Shanghai, China). Then, the cell-free extract was prepared as the crude enzyme using a Precellys 24 cell homogenizer (Bertin Technologies, France), as previously described (Shen et al. 2012). Protein concentration was measured using an Enhanced BCA Protein Assay Kit (Beyotime Biotechnology, China). The xylose isomerase activity of the crude enzyme was determined at $30{ }^{\circ} \mathrm{C}$ by measuring the absorbance change of the coenzymes at $340 \mathrm{~nm}$ with a spectrophotometer (Helios Gamma, Thermo Fisher Scientific, Waltham, MA). The 1-mL reaction mixture contained $100 \mathrm{mmol} \mathrm{L}^{-1}$ Tris- $\mathrm{HCl}$ buffer ( $\left.\mathrm{pH} 7.5\right)$, $10 \mathrm{mmol} \mathrm{L}^{-1} \mathrm{MgCl}_{2}, 500 \mathrm{mmol} \mathrm{L}^{-1}$ xylose, $2 \mathrm{U}$ of sorbitol dehydrogenase (Roche, Boulder, CO), $0.15 \mathrm{mmol} \mathrm{L}^{-1}$ $\mathrm{NADH}$, and crude enzyme (Kuyper et al. 2003). One unit of xylose isomerase activity was defined as the amount of enzyme required to oxidize $1 \mu \mathrm{mol}$ of coenzyme per minute under the conditions of the assay, and the specific activity was expressed in units per milligram of protein (Shen et al. 2012).

\section{Gene transcription level analysis}

Overnight cultures were transferred into fresh YPD20 medium with 0.2 initial $\mathrm{OD}_{600}$ and cultured at $30{ }^{\circ} \mathrm{C}$. Cells were harvested at $\mathrm{OD}_{600} 0.8-1.0$. Total RNA was isolated using Trizol reagent (Takara, Japan) and purified using a NucleoSpin ${ }^{\circledR}$ Extract II Kit (Machery-Nagel Corp., Germany). The total RNA $(0.25 \mu \mathrm{g})$ was used to synthesize the first strand of cDNA in a $10-\mu \mathrm{L}$ reverse transcription (RT) reaction. Real-time quantitative PCR was performed using the Light Cycle PCR System (Roche Molecular Biochemicals, Germany) and SYBR Green Real-time PCR Master Mix (TOYOBO, Japan). The normalization reference was ACT1 (Peng et al. 2012). The primers for the quantitative real-time PCR are listed in Additional file 1: Table S1. Real-time quantitative PCR data were analyzed according to the $2^{-\triangle \Delta C T}$ method (Livak and Schmittgen 2001). All data were the average of values from three separate cultures, and each culture was tested in triplicate. The replicates were compared using Student's $t$-test whenever indicated. A $P<0.05$ was considered statistically significant.

\section{Determination of gene copy number}

Cells were washed and resuspended in TE buffer $(10 \mathrm{mM}$ Tris-HCl, 1 mM EDTA, pH 7.5) and lysed with a Precellys 24 cell homogenizer (Bertin Technologies, France). The protein was removed using the phenol-chloroform method (Ellington \& Jack D. Pollard, in Short Protocols in Molecular Biology, Volume 1, 5th Edition. Edited by Frederick M. Ausubel, Roger Brent, Robert E. Kingston, David D. Moore, J. G. Seidman, John A. Smith, and Kevin Struhl. John Wiley \& Sons, Inc.). The genomic DNA was precipitated with ethanol, resuspended in water, and then used to analyze the gene copy number via quantitative real-time PCR. The normalization reference was $A C T 1$. The copy number was calculated according to the following equation: plasmid copy number $=2^{\mathrm{CT}(a c t 1)} / 2^{\mathrm{CT}(x y l A)}$ (Lee et al. 2006; Shen et al. 2012).

\section{Additional file}

Additional file 1. Table S1. Primers used in the current study. Figure S1. The relative locations of the introduced genes in each genomic locus. Figure S2. The physical maps of the plasmids.

\section{Abbreviations}

$\mathrm{XI}$ : xylose isomerase; $\mathrm{XR}$ : $x y$ lose reductase; $\mathrm{XDH}$ : $x y$ litol dehydrogenase; PPP: pentose phosphate pathway; SECS: steam-exploding corn stover; SPPR: sulfite pretreatment papermaking residue; SECS liquor: the leach liquor of steamexploding corn stover; YP: yeast extract and peptone; DCW: dry cell weight; g: grams; L: liter; h: hours; $\mathrm{OD}$ or $\mathrm{OD}_{600}$ : optical density at $600 \mathrm{~nm}$; RT-qPCR: quantitative reverse-transcription PCR; qPCR: quantitative real-time PCR.

\section{Authors' contributions}

$H X L, Y S, J H$ and XMB conceived of the study. HXL and MLW performed the experiments. CLJ, ZLL and XLL participated in the design of the study and helped with data analysis. HXL, YS and XMB analyzed the results and drafted the manuscript. All authors read and approved the final manuscript.

\section{Author details \\ ${ }^{1}$ State Key Laboratory of Microbial Technology, Shandong University, Shan Da Nan Road 27, Jinan 250100, China. ${ }^{2}$ Shandong Provincial Key Laboratory of Microbial Engineering, Qi Lu University of Technology, Jinan 250353, China.}

\section{Acknowledgements}

The authors wish to acknowledge the financial support from Project of National Energy Administration of China (NY20130402), National HighTechnology Research and Development Program of China under Grant (2014AA021903, 2012AA022106), National Key Technology R\&D Program of China (2014BAD02B07), National Natural Science Foundation of China (31470166, 31270151), the State Key Laboratory of Motor Vehicle Biofuel Technology (2013004, KFKT2013002). The work also supported by Shandong Key Laboratory of Straw Biorefinement Technologies and Taishan Scholar Construction Project.

\section{Competing interests}

The authors declare that they have no competing interests.

Availability of supporting data

All data generated or analyzed during this study are included in this article and its Additional files.

Received: 9 October 2016 Accepted: 11 November 2016

Published online: 24 November 2016 


\section{References}

Almeida JRM, Modig T, Petersson A, Hähn-Hägerdal B, Lidén G, GorwaGrauslund MF (2007) Increased tolerance and conversion of inhibitors in lignocellulosic hydrolysates by Saccharomyces cerevisiae. J Chem Technol Biotechnol 82:340-349. doi:10.1002/jctb.1676

Bamba T, Hasunuma T, Kondo A (2016) Disruption of PHO13 improves ethanol production via the xylose isomerase pathway. AMB Expres 6:4. doi:10.1186/s13568-015-0175-7

Bao X, Shen Y, GE R (2013) Nucleic acid molecule for encoding xylose isomerase and xylose isomerase encoded by the nucleic acid molecule. US Patent 8,586,336 B2, 19 Nov 2013. http://xs1.hntvchina.com/patents/ US8586336

Blazeck J, Garg R, Reed B, Alper HS (2012) Controlling promoter strength and regulation in Saccharomyces cerevisiae using synthetic hybrid promoters. Biotechnol Bioeng 109:2884-2895. doi:10.1002/bit.24552

Brandberg T, FranzéN CJ, Gustafsson L (2004) The fermentation performance of nine strains of Saccharomyces cerevisiae in batch and fed-batch cultures in dilute-acid wood hydrolysate. J Biosci Bioeng 98:122-125. doi:10.1016/ S1389-1723(04)70252-2

Brat D, Boles E, Wiedemann B (2009) Functional expression of a bacterial xylose isomerase in Saccharomyces cerevisiae. Appl Environ Microbiol 75:2304-2311

Cho KM, Yoo YJ, Kang HS (1999) $\delta$-Integration of endo/exo-glucanase and $\beta$-glucosidase genes into the yeast chromosomes for direct conversion of cellulose to ethanol. Enzyme Microb Technol 25:23-30. doi:10.1016/ s0141-0229(99)00011-3

Demeke M, Dietz H, Li Y, Foulquie-Moreno M, Mutturi S, Deprez S, Den Abt T, Bonini B, Liden G, Dumortier F et al (2013) Development of a D-xylose fermenting and inhibitor tolerant industrial Saccharomyces cerevisiae strain with high performance in lignocellulose hydrolysates using metabolic and evolutionary engineering. Biotechnol Biofuels 6:89. doi:10.1186/1754-6834-6-89

Diao L, Liu Y, Qian F, Yang J, Jiang Y, Yang S (2013) Construction of fast xylose-fermenting yeast based on industrial ethanol-producing diploid Saccharomyces cerevisiae by rational design and adaptive evolution. BMC Biotechnol 13:110

Farwick A, Bruder S, Schadeweg V, Oreb M, Boles E (2014) Engineering of yeast hexose transporters to transport $d$-xylose without inhibition by D-glucose. Proc Natl Acad Sci USA 111:5159-5164. doi:10.1073/ pnas. 1323464111

Fujitomi K, Sanda T, Hasunuma T, Kondo A (2012) Deletion of the PHO13 gene in Saccharomyces cerevisiae improves ethanol production from lignocellulosic hydrolysate in the presence of acetic and formic acids, and furfural. Bioresour Technol 111:161-166. doi:10.1016/j.biortech.2012.01.161

Güldener U, Heck S, Fiedler T, Beinhauer J, Hegemann JH (1996) A new efficient gene disruption cassette for repeated use in budding yeast. Nucleic Acids Res 24:2519-2524. doi:10.1093/nar/24.13.2519

Hahn-Hägerdal B, Karhumaa K, Fonseca C, Spencer-Martins I, Gorwa-Grauslund M (2007) Towards industrial pentose-fermenting yeast strains. Appl Microbiol Biotechnol 74:937-953. doi:10.1007/s00253-006-0827-2

Heer D, Sauer U (2008) Identification of furfural as a key toxin in lignocellulosic hydrolysates and evolution of a tolerant yeast strain. Microb Biotechnol 1:497-506. doi:10.1111/j.1751-7915.2008.00050.x

Ho NW, Chen Z, Brainard AP, Sedlak M (1999) Successful design and development of genetically engineered Saccharomyces yeasts for effective cofermentation of glucose and xylose from cellulosic biomass to fuel ethanol. Adv Biochem Eng Biotechnol 65:163-192

Hou J, Lages NF, Oldiges M, Vemuri GN (2009a) Metabolic impact of redox cofactor perturbations in Saccharomyces cerevisiae. Metab Eng 11:253261. doi:10.1016/j.ymben.2009.05.001

Hou J, Vemuri GN, Bao X, Olsson L (2009b) Impact of overexpressing NADH kinase on glucose and xylose metabolism in recombinant xyloseutilizing Saccharomyces cerevisiae. Appl Microbiol Biotechnol 82:909-919. doi:10.1007/s00253-009-1900-4

Hou J, Suo F, Wang CQ, Li XW, Shen Y, Bao XM (2014) Fine-tuning of NADH oxidase decreases byproduct accumulation in respiration deficient xylose metabolic Saccharomyces cerevisiae. BMC Biotechnol. doi:10.1186/1472-6750-14-13

Hou J, Shen Y, Jiao C, Ge R, Zhang X, Bao X (2016a) Characterization and evolution of xylose isomerase screened from the bovine rumen metagenome in Saccharomyces cerevisiae. J Biosci Bioeng 121:160-165. doi:10.1016/j. jbiosc.2015.05.014
Hou J, Jiao C, Peng B, Shen Y, Bao X (2016b) Mutation of a regulator Ask10p improves xylose isomerase activity through up-regulation of molecular chaperones in Saccharomyces cerevisiae. Metab Eng 38:241-250. doi:10.1016/j.ymben.2016.08.001

Jin Y-S, Ni H, Laplaza J, Jeffries T (2003) Optimal growth and ethanol production from xylose by recombinant Saccharomyces cerevisiae require moderate D-xylulokinase activity. Appl Environ Microbiol 69:495-503. doi:10.1128/AEM.69.1.495-503.2003

Kim SR, Park YC, Jin YS, Seo JH (2013) Strain engineering of Saccharomyces cerevisiae for enhanced xylose metabolism. Biotechnol Adv 31:851-861. doi:10.1016/j.biotechadv.2013.03.004

Ko JK, Um Y, Woo HM, Kim KH, Lee S-M (2016) Ethanol production from lignocellulosic hydrolysates using engineered Saccharomyces cerevisiae harboring xylose isomerase-based pathway. Bioresour Technol 209:290-296. doi:10.1016/j.biortech.2016.02.124

Kuyper M, Harhangi HR, Stave AK, Winkler AA, Jetten MSM, de Laat WTAM, den Ridder JJJ, Op den Camp HJM, van Dijken JP, Pronk JT (2003) High-level functional expression of a fungal xylose isomerase: the key to efficient ethanolic fermentation of xylose by Saccharomyces cerevisiae? FEMS Yeast Res 4:69-78. doi:10.1016/S1567-1356(03)00141-7

Kuyper M, Winkler AA, van Dijken JP, Pronk JT (2004) Minimal metabolic engineering of Saccharomyces cerevisiae for efficient anaerobic xylose fermentation: a proof of principle. FEMS Yeast Res 4:655-664. doi:10.1016/j. femsyr.2004.01.003

Kuyper M, Hartog MMP, Toirkens MJ, Almering MJH, Winkler AA, van Dijken JP, Pronk JT (2005a) Metabolic engineering of a xylose-isomerase-expressing Saccharomyces cerevisiae strain for rapid anaerobic xylose fermentation. FEMS Yeast Res 5:399-409. doi:10.1016/j.femsyr.2004.09.010

Kuyper M, Toirkens MJ, Diderich JA, Winkler AA, van Dijken JP, Pronk JT (2005b) Evolutionary engineering of mixed-sugar utilization by a xylosefermenting Saccharomyces cerevisiae strain. FEMS Yeast Res 5:925-934. doi:10.1016/j.femsyr.2005.04.004

Lee C, Kim J, Shin SG, Hwang S (2006) Absolute and relative OPCR quantification of plasmid copy number in Escherichia coli. J Biotechnol 123:273280. doi:10.1016/j.jbiotec.2005.11.014

Lee S-M, Jellison T, Alper H (2014) Systematic and evolutionary engineering of a xylose isomerase-based pathway in Saccharomyces cerevisiae for efficient conversion yields. Biotechnol Biofuels 7:122. doi:10.1186/ s13068-014-0122-X

Li H, Wu M, Xu L, Hou J, Guo T, Bao X, Shen Y (2015) Evaluation of industrial Saccharomyces cerevisiae strains as the chassis cell for second-generation bioethanol production. Microb Biotechnol 8:266-274. doi:10.1111/1751-7915.12245

Livak KJ, Schmittgen TD (2001) Analysis of relative gene expression data using real-time quantitative PCR and the $2^{-\triangle \triangle C T}$ method. Methods 25:402-408. doi:10.1006/meth.2001.1262

Madhavan A, Tamalampudi S, Ushida K, Kanai D, Katahira S, Srivastava A Fukuda H, Bisaria VS, Kondo A (2009) Xylose isomerase from polycentric fungus Orpinomyces: gene sequencing, cloning, and expression in Saccharomyces cerevisiae for bioconversion of xylose to ethanol. Appl Microbiol Biotechnol 82:1067-1078. doi:10.1007/s00253-008-1794-6

Moon J, Lewis Liu Z, Ma M, Slininger PJ (2013) New genotypes of industrial yeast Saccharomyces cerevisiae engineered with YXI and heterologous xylose transporters improve xylose utilization and ethanol production. Bio catal Agric Biotechnol 2:247-254. doi:10.1016/j.bcab.2013.03.005

Moysés DN, Reis VCB, Almeida JRMd, Moraes LMPd, Torres FAG (2016) Xylose Fermentation by Saccharomyces cerevisiae: challenges and prospects. Int J Mol Sci 17:207. doi:10.3390/ijms17030207

Nijland JG, Shin HY, de Jong RM, de Waal PP, Klaassen P, Driessen AJ (2014) Engineering of an endogenous hexose transporter into a specific D-xylose transporter facilitates glucose-xylose co-consumption in Saccharomyces cerevisiae. Biotechnol Biofuels 7:1-11. doi:10.1186/ s13068-014-0168-9

Palmqvist E, Hahn-Hägerdal B (2000) Fermentation of lignocellulosic hydrolysates. II: inhibitors and mechanisms of inhibition. Bioresour Technol 74:25-33. doi:10.1016/s0960-8524(99)00161-3

Pannunzio NR, Manthey GM, Liddell LC, Fu BXH, Roberts CM, Bailis AM (2012) Rad59 regulates association of Rad52 with DNA double-strand breaks. Microbiol Open 1:285-297. doi:10.1002/mbo3.31

Peng B, Chen X, Shen Y, Bao X (2011) Effect of controlled overexpression of xylulokinase by different promoters on xylose metabolism in Saccharomyces cerevisiae. Acta Microbiol Sin. 51(7):914-922 
Peng B, Shen Y, Li X, Chen X, Hou J, Bao X (2012) Improvement of xylose fermentation in respiratory-deficient xylose-fermenting Saccharomyces cerevisiae. Metab Eng 14:9-18. doi:10.1016/j.ymben.2011.12.001

Reider Apel A, Ouellet M, Szmidt-Middleton H, Keasling JD, Mukhopadhyay A (2016) Evolved hexose transporter enhances xylose uptake and glucose/ xylose co-utilization in Saccharomyces cerevisiae. Sci Rep 6:19512. doi:10.1038/srep19512

Robberecht C, Voet T, Esteki MZ, Nowakowska BA, Vermeesch JR (2013) Nonallelic homologous recombination between retrotransposable elements is a driver of de novo unbalanced translocations. Genome Res 23:411-418. doi:10.1101/gr.145631.112

Romaní A, Pereira F, Johansson B, Domingues L (2015) Metabolic engineering of Saccharomyces cerevisiae ethanol strains PE-2 and CAT- 1 for efficient lignocellulosic fermentation. Bioresour Technol 179:150-158. doi:10.1016/j.biortech.2014.12.020

Runquist D, Fonseca C, Rådström P, Spencer-Martins I, Hahn-Hägerdal B (2009) Expression of the Gxf1 transporter from Candida intermedia improves fermentation performance in recombinant xylose-utilizing Saccharomyces cerevisiae. Appl Microbiol Biotechnol 82:123-130. doi:10.1007/ s00253-008-1773-y

Salusjarvi L, Kankainen M, Soliymani R, Pitkanen J-P, Penttila M, Ruohonen L (2008) Regulation of xylose metabolism in recombinant Saccharomyces cerevisiae. Microb Cell Fact 7:18. doi:10.1 186/1475-2859-7-18

Sharma S, Sharma S, Singh S, Lata Arora A (2016) Improving yeast strains for pentose hexose co-fermentation: successes and hurdles. In: Kumar S, Khanal KS, Yadav KY (eds) Proceedings of the first international conference on recent advances in bioenergy research. Springer Proceedings in Energy. Springer, New Delhi

Shen Y, Chen X, Peng B, Chen L, Hou J, Bao X (2012) An efficient xylose-fermenting recombinant Saccharomyces cerevisiae strain obtained through adaptive evolution and its global transcription profile. Appl Microbiol Biotechnol 96:1079-1091. doi:10.1007/s00253-012-4418-0

Shin HY, Nijland JG, de Waal PP, de Jong RM, Klaassen P, Driessen AJ (2015) An engineered cryptic Hxt11 sugar transporter facilitates glucose-xylose co-consumption in Saccharomyces cerevisiae. Biotechnol Biofuels 8:176. doi:10.1186/s13068-015-0360-6

Singleton VL, Orthofer R, Lamuela-Raventós RM (1999) Analysis of total phenols and other oxidation substrates and antioxidants by means of folinciocalteu reagent. In: Pecoraro Vincent L (ed) Oxidants and antioxidants Part A methods in enzymology, vol 299. Academic Press, New York, pp $152-178$

Smith J, van Rensburg E, Goergens JF (2014) Simultaneously improving xylose fermentation and tolerance to lignocellulosic inhibitors through evolutionary engineering of recombinant Saccharomyces cerevisiae harbouring xylose isomerase. BMC Biotechnol 14:41. doi:10.1186/1472-6750-14-41

Sonderegger M, Jeppsson M, Larsson C, Gorwa-Grauslund MF, Boles E, Olsson L, Spencer-Martins I, Hahn-Hagerdal B, Sauer U (2004) Fermentation performance of engineered and evolved xylose-fermenting Saccharomyces cerevisiae strains. Biotechnol Bioeng 87:90-98. doi:10.1002/bit.20094

Subtil T, Boles E (2012) Competition between pentoses and glucose during uptake and catabolism in recombinant Saccharomyces cerevisiae. Biotechnol Biofuels 5:1. doi:10.1186/1754-6834-5-14

Tan L, Yu Y, Li X, Zhao J, Qu Y, Choo YM, Loh SK (2013) Pretreatment of empty fruit bunch from oil palm for fuel ethanol production and proposed biorefinery process. Bioresour Technol 135:275-282. doi:10.1016/j. biortech.2012.10.134

van Maris AJ, Abbott DA, Bellissimi E, van den Brink J, Kuyper M, Luttik MA, Wisselink HW, Scheffers WA, van Dijken JP, Pronk JT (2006) Alcoholic fermentation of carbon sources in biomass hydrolysates by Saccharomyces cerevisiae: current status. Antonie Van Leeuwenhoek 90:391-418. doi:10.1007/s10482-006-9085-7

Van Vleet J, Jeffries T (2009) Yeast metabolic engineering for hemicellulosic ethanol production. Curr Opin Biotechnol 20:300-306. doi:10.1016/j. copbio.2009.06.001
Van Vleet J, Jeffries T, Olsson L (2008) Deleting the para-nitrophenyl phosphatase (pNPPase), PHO13, in recombinant Saccharomyces cerevisiae improves growth and ethanol production on D-xylose. Metab Eng 10:360-369. doi:10.1016/j.ymben.2007.12.002

Walfridsson M, Bao X, Anderlund M, Lilius G, Bülow L, Hahn-Hägerdal B (1996) Ethanolic fermentation of xylose with Saccharomyces cerevisiae harboring the Thermus thermophilus xylA gene, which expresses an active xylose (glucose) isomerase. Appl Environ Microbiol 62:4648-4651

Walfridsson M, Anderlund M, Bao X, Hahn-Hagerdal B (1997) Expression of different levels of enzymes from the Pichia stipitis XYL1 and XYL2 genes in Saccharomyces cerevisiae and its effects on product formation during xylose utilisation. Appl Microbiol Biotechnol 48:218-224. doi:10.1007/ s002530051041

Wang Y, Shi W-L, Liu X-Y, Shen Y, Bao X-M, Bai F-W, Qu Y-B (2004) Establishment of a xylose metabolic pathway in an industrial strain of Saccharomyces cerevisiae. Biotechnol Lett 26:885-890. doi:10.1023/B:b ile.0000025897.21106.92

Wang C, Bao X, Li Y, Jiao C, Hou J, Zhang Q, Zhang W, Liu W, Shen Y (2015) Cloning and characterization of heterologous transporters in Saccharomyces cerevisiae and identification of important amino acids for xylose utilization. Metab Eng 30:79-88. doi:10.1016/j.ymben.2015.04.007

Wang M, Yu C, Zhao H (2016) Directed evolution of xylose specific transporters to facilitate glucose-xylose co-utilization. Biotechnol Bioeng 113:484491. doi:10.1002/bit.25724

Xu H, Kim S, Sorek H, Lee Y, Jeong D, Kim J, Oh EJ, Yun EJ, Wemmer DE, Kim KH (2016) PHO13 deletion-induced transcriptional activation prevents sedoheptulose accumulation during xylose metabolism in engineered Saccharomyces cerevisiae. Metab Eng 34:88-96. doi:10.1016/j. ymben.2015.12.007

Yamada R, Tanaka T, Ogino C, Fukuda H, Kondo A (2010) Novel strategy for yeast construction using $\delta$-integration and cell fusion to efficiently produce ethanol from raw starch. Appl Microbiol Biotechnol 85:1491-1498. doi:10.1007/s00253-009-2198-y

Yamada R, Taniguchi N, Tanaka T, Ogino C, Fukuda H, Kondo A (2011) Direct ethanol production from cellulosic materials using a diploid strain of Saccharomyces cerevisiae with optimized cellulase expression. Biotechnol Biofuels 4:8. doi:10.1186/1754-6834-4-8

Zha J, Hu ML, Shen MH, Li BZ, Wang JY, Yuan YJ (2012) Balance of XYL1 and $X Y L 2$ expression in different yeast chassis for improved xylose fermentation. Front Microbiol 3:355. doi:10.3389/fmicb.2012.00355

Zhang X, Shen Y, Shi W, Bao X (2010) Ethanolic cofermentation with glucose and xylose by the recombinant industrial strain Saccharomyces cerevisiae NAN-127 and the effect of furfural on xylitol production. Bioresour Technol 101:7104-7110. doi:10.1016/j.biortech.2010.03.129

Zhou H, J-s Cheng, Wang BL, Fink GR, Stephanopoulos G (2012) Xylose isomerase overexpression along with engineering of the pentose phosphate pathway and evolutionary engineering enable rapid xylose utilization and ethanol production by Saccharomyces cerevisiae. Metab Eng 14:611-622. doi:10.1016/j.ymben.2012.07.011

\section{Submit your manuscript to a SpringerOpen ${ }^{\circ}$ journal and benefit from:}

- Convenient online submission

- Rigorous peer review

- Immediate publication on acceptance

- Open access: articles freely available online

- High visibility within the field

- Retaining the copyright to your article

Submit your next manuscript at springeropen.com 